\title{
Experimental study on the vibration mitigation of offshore tension leg platform system with UWTLCD
}

\author{
Hsien Hua Lee* and H.H. Juang \\ Department of Marine Environment and Engineering, National Sun Yat-sen University, Kaohsiung, Taiwan
}

(Received August 19, 2010, Revised March 2, 2011, Accepted December 20, 2011)

\begin{abstract}
In this research, a typical tension-leg type of floating platform incorporated with an innovative concept of underwater tuned liquid column damper system (UWTLCD) is studied. The purpose of this study is to improve the structural safety by means of mitigating the wave induced vibrations and stresses on the offshore floating Tension Leg Platform (TLP) system. Based on some encouraging results from a previous study, where a Tuned Liquid Column Damper (TLCD) system was employed in a floating platform system to reduce the vibration of the main structure, in this study, the traditional TLCD system was modified and tested. Firstly, the orifice-tube was replaced with a smaller horizontal tube and secondly, the TLCD system was combined into the pontoon system under the platform. The modification creates a multipurpose pontoon system associated with vibration mitigation function. On the other hand, the UWTLCD that is installed underwater instead would not occupy any additional space on the platform and yet provide buoyancy to the system. Experimental tests were performed for the mitigation effect and parameters besides the wave conditions, such as pontoon draught and liquid-length in the TLCD were taken into account in the test. It is found that the accurately tuned UWTLCD system could effectively reduce the dynamic response of the offshore platform system in terms of both the vibration amplitude and tensile forces measured in the mooring tethers.
\end{abstract}

Keywords: vibration mitigation; Under Water TLCD (UWTLCD); TLP system; experimental water tank testing; stochastic analysis.

\section{Introduction}

An experimental study on the vibration mitigation for an offshore floating platform system of tension leg type is presented in this study. The platform subjected to surge motion incorporates a TLCD (Tuned Liquid Column Damper) device. The offshore platform has been widely applied as an operation station for offshore exploitation, floating breakwater, offshore fish-farming platform and offshore recreation facility. The latest development for the TLP system is the application for the offshore windmill (Boschetti 2006), where a wind turbine in a very deep sea was designed to be installed on a floating foundation.

Many kinds of loading may exert on an offshore platform and result in serious vibrations, instability and damages of the structure. Vibrations not only gradually damage the platform's structural system but also cause an uncomfortable environment for humans. Therefore, the vibration of the platform becomes an important issue along with the safety requirement, particularly when facilities of recreation and entertainment purposes are installed on the platform system. It is always

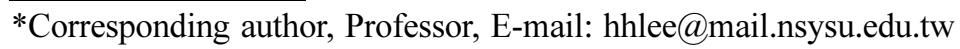


a challenging task to try to reduce the vibration induced by waves, flow or wind loading, because of difficulties with monitoring accurately the platform motion and lack of an appropriate mitigation device that can be employed on an offshore structural system.

In order to accurately monitor the platform motions, many investigations have been carried out depending on the platform type. ForTension-Leg Platform systems developed for the offshore deepsea exploitation, many investigations could be found in two major categories. Those investigation included issue mainly focused on the wave-structure interaction problems (Mei 1978, Yamamoto et al. 1982, Lee and Wang 2001 2003) and issues on the nonlinear behavior of platforms by using a small body assumption for the analyzing objects in the ocean (Jain 1997, Chatterjee et al. 1997). While many efforts have been put in the study for the fundamental behavior of platform and waves, rare attention (Brogan and Wasserman 2003) has been paid on the structural safety of an offshore structural system in water, particularly damages caused by vibrations due to the action of waves. Several studies focused on vibration mitigation to enhance structural safety for template type offshore platform (Lee and $\mathrm{Wu}$ 1996, Lee 1998); however, there is a lack of studies relevant to floating structural system, even though these ones face more severe environmental challenges. Only recently, the mitigation of vibration for floating platform systems was addressed (Lee et al. 2006), where the TLCD (Tuned Liquid Column Damper) was incorporated in a platform system, which was supported by buoyant members and anchored with pre-stressed tethers. Later on, Colwell and Basu (2009) also made a stochastic study using a scheme similar to the one proposed by Lee (1997) by utilizing TLCD damping system to control the vibration of an offshore wind turbine system. Another vibration mitigation scheme, a mass damper, was also proposed and applied to mitigation of a TLP system (Taflanidis et al. 2009).

The TLCD system, a device by utilizing the water sloshing power to reduce the vibrations of the main structure induced from environmental loadings, has been developed for more than a decade. This device has been utilized to mitigate the vibration for the traditional civil structures such as applications to the structures in Sakitama Bridge and Shin Yokohama Prince Hotel in Japan (Fujino and Sun 1993), where the effectiveness for the vibration reduction was also verified. The TLCD was extended from the TLD (Tuned Liquid Damper) device which has been widely discussed and studied in the late 80s and early 90s (Fujino et al. 1988, 1992, Chaiseri et al. 1989). The TLCD is a U-shape tube-like device that contains water or similar liquid. The liquid passing through a small orifice at the center of cross section of the tube causes hydraulic head loss of the liquid and then reduces the vibration of the associated main structure. The damping effect associated with the hydraulic head loss of the liquid, induced by the orifice at the cross section was firstly studied by Sakai et al. (1989). In a study for the application of the TLCD system to the tower type structure, Balendra et al. (1995) provided a relationship between the tower height and the opening ratio for the orifice. The application of TLCD system to the multi-degree-of-freedom structures was also studied by Won et al. (1996)using random vibration analysis for the earthquake excitation.

Subsequently, many improvement ideas for the TLCD system have been proposed such as the variable orifice system or so called pressure control mechanism (Kareem and Kline 1995) and the studies on the characteristics of variable cross section between the horizontal and vertical tube (Hichhock et al. 1997a,b, Gao and Kwok 1997). Gao and Kwoks' (1997) found in numerical study that the increase of the cross section of the horizontal tube would imply reduction of the liquid column in the vertical tube, and appropriate parameters could be obtained to reduce the amplification factor when the structure was subjected to a harmonic vibration. Applications for multiple TLCD were also studied for reducing coupled lateral and torsional vibration of structures (Shum and Xu 2004). 
A design guideline was also proposed by Wu et al. (2005) for a TLCD applied to structures responding to wind loading.

Although the application of TLCD to on-land structural buildings had encouraging results, the application of the TLCD to offshore structural systems was not found until Lee presented a theoretical study (Lee et al. 2006). It showed that after appropriate design, the TLCD system could be a promising device to reduce the wave induced vibration for the offshore platform structural system. However, what presented in that study is basically, a theoretical study in the frequency domain along with an innovative feasibility experimental study. First of all, due to the random nature of waves, the stochastic analytical method in the frequency domain was utilized and because of this, a linearization scheme for the system was also applied in Lee's study. Therefore, only results in the frequency domain were presented and as was mentioned, a linear system must be presumed. Moreover, the experimental study was also performed in quite scratchy way, as a video camera was utilized to trace the motion of the platform under testing instead of using measurement tools with better resolutions for the laboratory testing. By using a video camera, the framed image at each chosen time-step must be analyzed and recalculated for reducing the effect of the shooting angle, furthermore, because the motion is not restrained in one direction an error is usually inevitable, which then influences the final experimental results.

Therefore, it is the purpose of this study through an appropriately designed experimental testing method to investigate the vibration mitigation effect of a Tension Leg Platform system equipped with a UWTLCD device and subjected to surge wave motion. In this study, an innovative underwater TLCD (UWTLCD) device with reduced size of horizontal tubes was applied for the first time to an offshore platform structural system. For this newly developed UWTLCD device installed under the deck of a Tension Leg Platform system, it is assumed that there is no relative motion between the structure and the UWTLCD.

\section{Equation of motion for the platform with TLCD}

Fig. 1 is a typical Tension Leg Platform with vertical buoyant members of 2-dimension combined with an innovative under water TLCD device (UWTLCD). Illustrated in Fig. 2 is a modified TLCD device composed of two vertical square columns connected with a horizontal circular tube, where

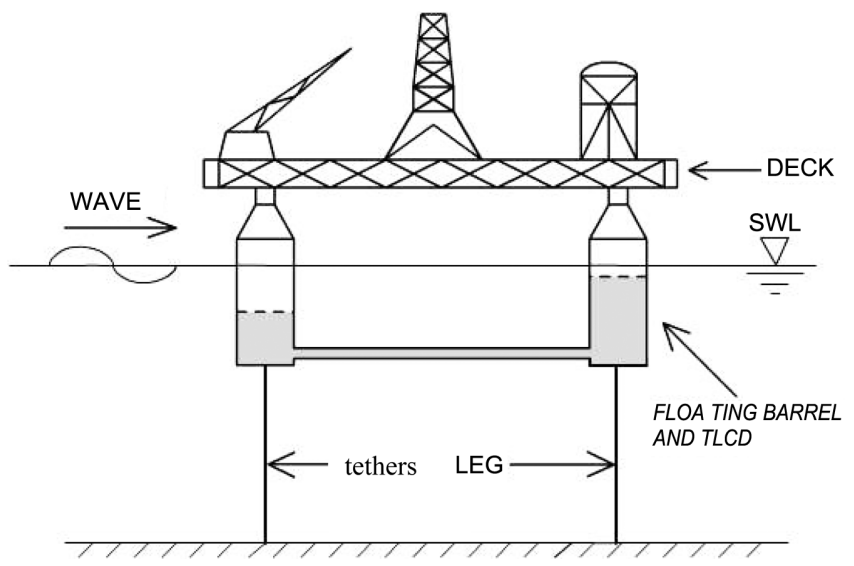

Fig. 1 Schematic view of an offshore platform installed with a TLCD device 


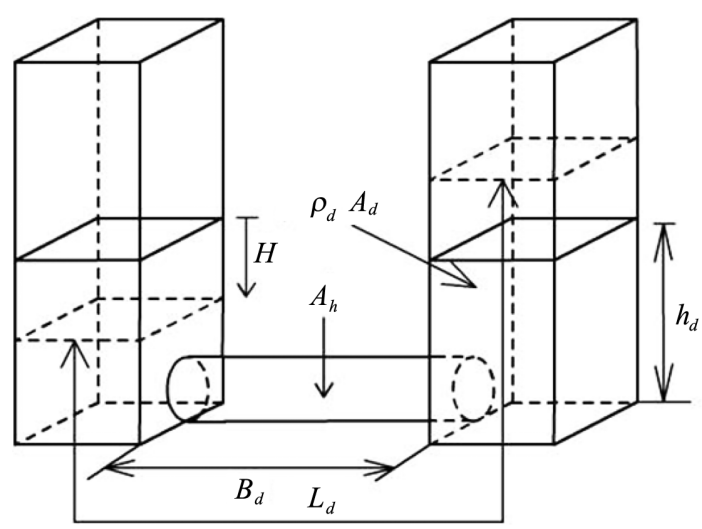

Fig. 2 Schematic drawing of TLCD with confined horizontal tube

the liquid is filled inside. It is noticed that the cross section of the horizontal tube is smaller compared to the vertical columns. The area ratio of cross section between the vertical square column and horizontal circular tube is determined through an optimization process (Lee et al. 2006). Similar to the traditional TLCD device, where a small orifice is placed right at the middle cross section of the horizontal tube that has the same cross section-area as the vertical ones, this smaller horizontal tube also provides damping effect when the liquid inside the tube is sloshing from one column toward the other. The UWTLCD system could provide similar damping effect for an offshore platform system compared to the traditional orifice-type TLCD system; however, it presents some more advantages over the TLCD system. Firstly, since the UWTLCD system is installed beneath the platform, both the deck space and the buoyant force of the platform can be saved for operational service. Secondly, after combined with vertical buoyant members, the vertical column of UWTLCD can serve partly as a buoyant member.

The equation of motion for the liquid in the tube is modified from the traditional one, where an orifice is opened in the middle section of the horizontal tube (Sakai et al. 1989). As indicated in Fig. 2, the length of the constricted horizontal tube is $B_{d}$, the original height of the liquid in the vertical column is $h_{d}$ and the area of the cross section for the vertical column and the constricted horizontal tube is $A_{d}$ and $A_{h}$ respectively. The liquid filled in the tube is sloshing due to the vibration of the main structure.

As shown in Fig. 2, where three volumes of liquid body $V_{1}, V_{2}$ and $V_{3}$ correspond to the volume of liquid in the left-hand side column, horizontal tube and right-hand side column, the vibration induced sloshing of liquid and corresponding energy are calculated and balanced based on the theorem of conservation of energy in the TLCD system. By applying the Lagrange equation for the kinetic energy, $T$, and potential energy, $U$, of the fluid and the non-conservative force, $\Omega$, exerting on the system, the equation of motion for the liquid filled inside the column-tube can be obtained through

$$
\frac{d}{d t}\left[\frac{\partial(T-U)}{\partial \dot{H}}\right]-\frac{\partial(T-U)}{\partial H}=\Omega
$$

The kinetic energy $T$ of the fluid can be defined as

$$
T=\int_{V_{1}} \frac{\dot{H}^{2}}{2} \rho_{d} d V+\int_{V_{2}} \frac{\left(\beta_{d} \dot{H}+\dot{X}\right)^{2}}{2} \rho_{d} d V+\int_{V_{3}} \frac{\dot{H}^{2}}{2} \rho_{d} d V
$$




$$
=\rho_{d} A_{d} h_{d} \dot{H}^{2}+\rho_{d} A_{h} B_{d} \frac{\left(\beta_{d} \dot{H}+\dot{X}\right)^{2}}{2}
$$

where $\dot{X}$ is the horizontal velocity of the main structure. Parameter $\rho_{d}$ is the density of the liquid; $H, \dot{H}$ and $\ddot{H}$ are the vertical displacement, velocity and acceleration of the liquid inside the column-tube respectively while the area ratio between the cross section of the vertical column and horizontal tube is $\beta_{d}=\frac{A_{d}}{A_{h}} \geq 1$. The potential energy of the fluid $U$ is presented as

$$
\begin{gathered}
U=\int_{V_{1}} g z \rho_{d} d V+\int_{V_{3}} g z \rho_{d} d V=\rho_{d} g A_{d} \int_{0}^{h_{d}-H} z d z+\rho_{d} g A_{d} \int_{0}^{h_{d}+H} z d z \\
=\rho_{d} g A_{d}\left(h_{d}^{2}+H^{2}\right)
\end{gathered}
$$

where $g$ is the acceleration of gravity. The non-conservative force $\Omega$ induced from the drag of the fluid in the horizontal tube is defined as

$$
\Omega=-\left(\rho_{d} g A_{h}\right)\left(\frac{h_{d}\left|\beta_{d} \dot{H}\right| \beta_{d} \dot{H}}{2 g}\right)=-\frac{1}{2} \rho_{d} A_{d} \beta_{d} h_{d}|\dot{H}| \dot{H}
$$

By substituting Eqs. (2), (3) and (4) into Eq. (1) it is obtained

$$
\rho_{d} A_{d} L_{e} \ddot{H}+\frac{1}{2} \rho_{d} A_{d} \beta_{d} h_{d}|\dot{H}| \dot{H}+2 \rho_{d} A_{d} g H=-\rho_{d} A_{d} B_{d} \ddot{X}
$$

where $\ddot{X}$ is the acceleration of the main structure equipped with a TLCD; parameter $L_{e}$ is defined as the effective length such that

$$
L_{e}=\left(\beta_{d}-1\right) B_{d}+L_{d}
$$

It is observedfrom this equation, compared to the equation of the traditional type of TLCD system, that instead of the original length $L_{d}$ the effective length $L_{e}$ of the liquid has been used, while a parameter, $\beta_{d}$, representing a reduced cross section of horizontal tube was applied.

In considering the 2 dimensional, 3 degree of freedom motion (surge as $X$, heave as $Y$ and pitch as $\theta$ and the corresponding velocity and acceleration), the equations of motion modified from previous studies (Xue et al. 2000, Lee et al. 2006) by incorporating with Eq. (5) for the UWTLCD device in a TLP system equipped with two sets of UWTLCD devices are presented as

$$
\begin{gathered}
M \ddot{X}+C_{X} \dot{X}+K_{X} X=F-2 \rho_{d} A_{d} L_{e} \ddot{X}-\rho_{d} A_{d} B_{e} \beta_{d} \ddot{H} \\
M \ddot{Y}+C_{Y} \dot{Y}+K_{Y} Y=-4 \rho_{d} A_{d} H \ddot{H}-2 \rho_{d} A_{d} L_{e} \ddot{Y} \\
M_{R} \ddot{\theta}+C_{R} \dot{\theta}+K_{R} \theta=2 \rho_{d} A_{d}\left(L_{d}-B_{d}\right)\left(\bar{h}-\frac{1}{2} B_{d}\right) \ddot{H}+\rho_{d} A_{d} h_{d}|\dot{H}| \bar{h} \dot{H}+4 \rho_{d} A_{d} g \bar{h} H
\end{gathered}
$$

Parameter $M$ is the mass of the platform system and $M_{R}$ is the mass moment of inertia corresponding to pitch motion while $C_{X}, C_{Y}$ and $C_{R}$ are the corresponding damping coefficients. Parameter $F$ is the wave force dependent on both the waves and the structure submerged in the water. The parameters $K_{X}, K_{Y}$ and $K_{R}$ are the stiffness corresponding to the surge, heave and pitch motion of the platform respectively (Lee $e t$ al. 2006, Lee and Wang 2001).

It is noticed that nonlinear terms are included in Eqs. (5), (8) and (9). The nonlinear term $\dot{H}|\dot{H}|$ is 
due to the drag associated with the motion of the liquid in the tube. A technique of equivalent linearization (Wen 1980, Xu et al. 1992) is adopted here for those nonlinear terms in the equations. Assuming zero-mean stationary Gaussian process for the velocity $\dot{H}$, the equation of motion for the liquid is rewritten as

$$
m_{e} \ddot{H}+\beta_{d} c_{d} \dot{H}+2 \rho_{d} A_{d} g H=-\rho_{d} A_{d} B_{d} \ddot{X}
$$

where the mass $m_{e}=\rho_{d} A_{d} L_{e}$ and natural frequency $\omega_{d}=\sqrt{2 g / L_{e}}$ with $g$ as the gravitational constant. The equivalent damping coefficient $c_{d}$ is obtained through the minimization of the error $\varepsilon$ between the exact nonlinear drag damping and the equivalent one as

$$
\varepsilon=\left(\frac{m_{e} h_{d}}{2 L_{e}}\right)|\dot{H}|-c_{d}
$$

After carrying out the minimization for this error the equivalent damping coefficient is obtained as

$$
c_{d}=\sqrt{\frac{2}{\pi}} \rho_{d} A_{d} h_{d} \sigma_{\dot{H}}
$$

where $\sigma_{\dot{H}}$ is the standard deviation of the velocity of the liquid in the tube. By employing the same technique, the first term at the right-hand side of Eq. (8) can be written as

$$
\rho_{d} A_{d} H \ddot{H}=Q \ddot{H}
$$

where $Q=4 \sqrt{\frac{2}{\pi}} \rho_{d} A_{d} \sigma_{H}$ and $\sigma_{H}$ is the standard deviation of the liquid displacement.

Now by substituting Eq. (13) back into Eq. (8), employing the equivalent damping technique of Eq. (12) for the nonlinear drag term in Eq. (9) and combining Eq. (10) of the motion for the liquid of the double TLCD devices, and Eqs. (7)-(9) of the motions for the surge, heave and pitch of the platform structure,the matrix form of Eq. (14) is obtained

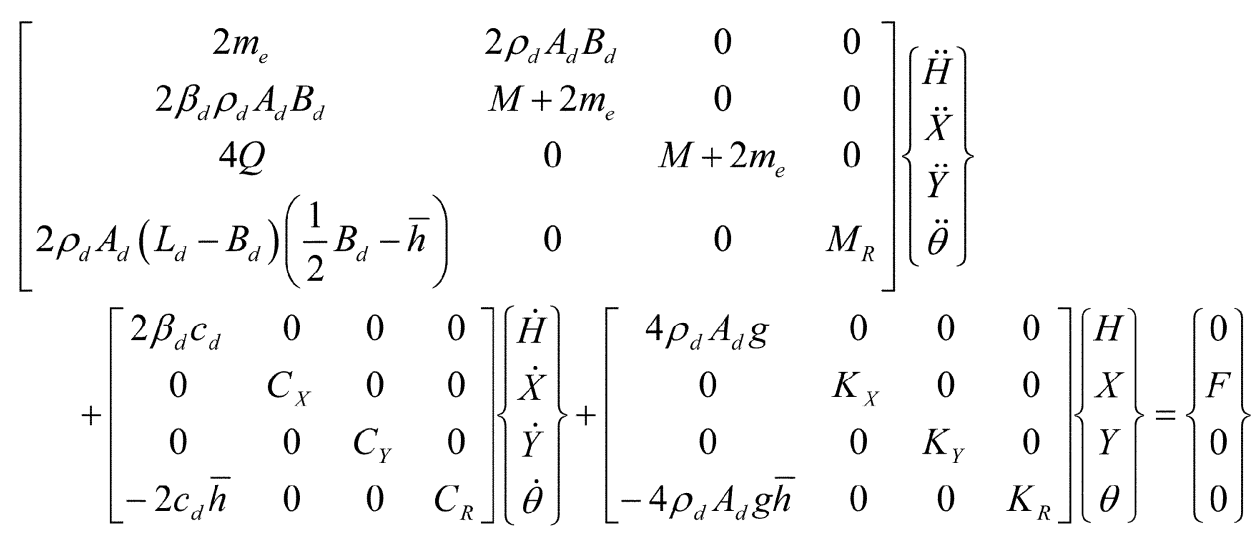

The excitation force on the unit length of the vertical buoyant member the surge direction by the wave is given by a modified Morison's equation (Newman 1977, Isaacson 1979) as

$$
f(t)=\rho C_{m} \Gamma \dot{u}-\rho C_{a} \Gamma \ddot{X}+\frac{1}{2} \rho C_{d} b|u-\dot{X}|(u-\dot{X})
$$


or alternatively, after employing the linearization technique for the nonlinear drag term, as

$$
f(t)=\rho C_{m} \Gamma \dot{u}-\rho C_{a} \Gamma \ddot{X}+\frac{1}{2} \rho C_{d} b|u| u-\rho C_{d} b \cdot\langle|u|\rangle \dot{X}
$$

where $\langle|u|\rangle$ is the time average of the fluid velocity $u ; C_{a}=C_{m}-1$ is the coefficient of added mass while $C_{m}$ is the inertia coefficient and $C_{d}$ is the drag coefficient. $\Gamma$ is the area of cross section of the vertical floating member (in this study it is the vertical column tube of TLCD device); $\rho$ is the density of the seawater, and $b$ is the dimension of the TLP structural member normal to the incoming wave. Now after the integration of the wave force on the unit length of the member of the TLP, the equations of motion accounting for the total wave force, added mass and drag effect on the damping can further be presented as

$$
\begin{aligned}
& {\left[\begin{array}{cccc}
2 m_{e} & 2 \rho_{d} A_{d} B_{d} & 0 & 0 \\
2 \beta_{d} \rho_{d} A_{d} B_{d} & M^{*}+2 m_{e} & 0 & 0 \\
4 Q & 0 & M+2 m_{e} & 0 \\
2 \rho_{d} A_{d}\left(L_{d}-B_{d}\right)\left(\frac{1}{2} B_{d}-\bar{h}\right) & 0 & 0 & M_{R}
\end{array}\right]\left\{\begin{array}{c}
\ddot{H} \\
\ddot{X} \\
\ddot{Y} \\
\ddot{\theta}
\end{array}\right\}+} \\
& {\left[\begin{array}{cccc}
2 \beta_{d} c_{d} & 0 & 0 & 0 \\
0 & C_{X}^{*} & 0 & 0 \\
0 & 0 & C_{Y} & 0 \\
-2 c_{d} \bar{h} & 0 & 0 & C_{R}
\end{array}\right]\left\{\begin{array}{c}
\dot{H} \\
\dot{X} \\
\dot{Y} \\
\dot{\theta}
\end{array}\right\}+\left[\begin{array}{cccc}
4 \rho_{d} A_{d} g & 0 & 0 & 0 \\
0 & K_{X} & 0 & 0 \\
0 & 0 & K_{Y} & 0 \\
-4 \rho_{d} A_{d} g \bar{h} & 0 & 0 & K_{R}
\end{array}\right]\left\{\begin{array}{c}
H \\
X \\
Y \\
\theta
\end{array}\right\}=\left\{\begin{array}{c}
0 \\
F \\
0 \\
0
\end{array}\right\}}
\end{aligned}
$$

where $M^{*}=M+\rho C_{a} \forall$, with $\forall=\int \Gamma d s$ the submerged volume of the members of the TLP; the damping accounting for the drag of the waves is $C_{X}^{*}=C_{X}+\rho C_{d} b \int\langle|u|\rangle d s$ while the total wave force is obtained through integration over the submerged depth of the members of the TLP (mostly tethers and UWTLCD in this study) as

$$
F(t)=\frac{1}{2} \rho b C_{d} \int u|u| d s+\rho \Gamma C_{m} \int \dot{u} d s
$$

It is noticed that the horizontal tube of the UWTLCD device is also submerged in the water and therefore, it is needed to take account of the wave force induced from the projected area of the horizontal tube. However, in the experimental test, since the longitudinal axis of the tube is not normal to but along with the wave direction, the wave force calculated from the projected area of the horizontal tube of the UWTLCD is small.

\section{Experimental set-up for the platform equipped with UWTLCD system}

Following an innovative feasibility experimental test (Lee et al. 2006), this test was further modified with many improvements such as more accurate data acquisition system and considerations with more degree of freedom system for the floating platform equipped with UWTLCD devices. For this innovative experimental study, the schematic sketch for the test set-up is illustrated in Fig. 3, where a scaled down model of the platform equipped with the UWTLCD device is installed in a water 


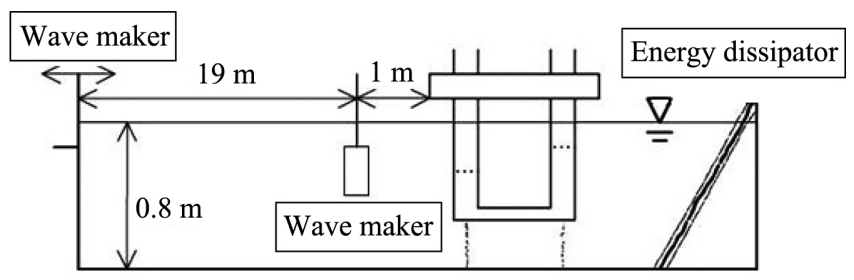

Fig. 3 The testing set-up in the water tank with wave maker

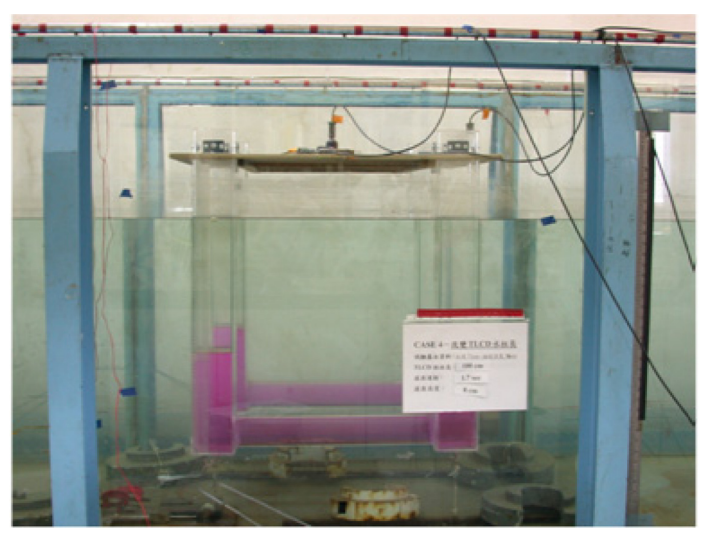

Fig. 4 The platform with TLCD device under testing

tank. Fig. 4 shows the photograph of the platform equipped with the UWTLCD device under testing in the water tank.

\subsection{Experimental set-up}

Testing set-ups consist of the water tanks, controlling systems and data acquisition systems, which include amplifiers and computers. The testing water tank located in the National Sun Yat-sen University, Taiwan is $30 \mathrm{~m}$ long, $1 \mathrm{~m}$ wide and $1.2 \mathrm{~m}$ high. At the left end of the tank, a pistontype hydraulic wave maker is installed, while at the right end of the tank the energy dissipation device of an inclined multi-layer screening surface is placed to reduce the reflected waves. The data acquisition facilities include the wave meters of electro-capacity type, accelerometers, portable dynamic strain amplifiers, strain gauge, electric-bridge box, power suppliers and computers.

The testing water tank is capable of making a wave of 2.8 seconds period and of $12 \mathrm{~cm}$ high amplitude. The accelerometers were utilized to measure the surge (horizontal), heave (vertical) and pitch (rotational) motions of three degree of freedom platform system. The strain gauges for the measurement of the variation of pretension forces were applied to the tethers of the platform to measure the tension forces.

\subsection{Testing model and dimensional analysis}

The testing model is constructed with wood as well as the polymer material, while a pair of Ushape, glass-wise tubes are attached under the bottom of the deck of the platform serving as both a UWTLCD damping device and the floating part of the platform system. The water is filled up to 
the designed level in both tubes. The dimension of the platform is $0.8 \mathrm{~m} \times 0.8 \mathrm{~m}$ and the buoyant columns (now the vertical columns of UWTLCD) are $0.75 \mathrm{~m}$ long with $0.1 \mathrm{~m} \times 0.1 \mathrm{~m}$ section-area anchored to the bed of the tank with strained tethers. These two columns (vertical tubes) are connected to each other by a smaller size circular pipe of diameter $0.7 \mathrm{~cm}$. The ratio of the sectional areas the vertical over the horizontal tubes is 2.6 obtained from optimum analysis (Lee 2006).

For the scaled-down test, a dimensional analysis was performed according to the similarity theorem. Since this experimental test is related toflow behavior with free surface, the inertia force, the gravity force and therefore, the Froude number become the most important factors; consequently, the Froude similarity is applied. The Froude similarity is presented as

$$
F_{s}=\sqrt{\frac{\text { inertial force }}{\text { gravity force }}}=\sqrt{\frac{\rho L^{2} V^{2}}{\rho L^{3} g}}=\frac{V}{\sqrt{g L}}
$$

where $V$ is the velocity of the flow; $g$ is the gravity; $L$ is the characteristic length. The relationship between the model and the prototype becomes as

$$
\left[\frac{V}{\sqrt{g L}}\right]_{m}=\left[\frac{V}{\sqrt{g L}}\right]_{p}
$$

where the subscript $m$ means model, while subscript $p$ means the prototype.

Assuming that the scale ratio of this testing model is $\lambda$ as

$$
\lambda=\left(\frac{L_{m}}{L_{p}}\right)
$$

Then, from the relationship between the model and prototype, the scale ratio for the period, waveheight, mass, and wave-force can be obtained as

Scale ratio of period: $\frac{T_{m}}{T_{p}}=\sqrt{\lambda}$

Scale ratio of wave-height: $\frac{H_{m}}{H_{p}}=\sqrt{\lambda}$

Scale ratio of mass: $\frac{M_{m}}{M_{p}}=\frac{\rho_{m} \times L_{m}^{3}}{\rho_{p} \times L_{p}^{3}}=N_{D} \lambda^{3}$

Scale ratio of wave-force: $\frac{F_{m}}{F_{p}}=\frac{M_{m} \times g_{m}}{M_{p} \times g_{p}}=\frac{\rho_{m} \times L_{m}^{3} \times g_{m}}{\rho_{p} \times L_{p}^{3} \times g_{p}}=N_{D} \lambda^{3}$

where $N_{D}$ is the scale ratio of the density. Because the density between the water and sea water is very close to each other, then we may assume the scale ratio $N_{D}=1$. The gravity force applied to the model platform and the prototype is the same, thus $g_{m}=g_{p}$.

\subsection{Testing sequences and wave conditions}

The testing purpose is to find the effectiveness of the vibration mitigation for the offshore platform equipped with UWTLCD system. Therefore, parameters such as the wave properties, amount of the 
Table 1 Design wave conditions in experimental tests

\begin{tabular}{|c|c|c|c|c|c|c|}
\hline Testing sequence & Depth & Period & Wave height & Wave length & Wave number $k$ & Steepness $\frac{H}{L}$ \\
\hline 1 & $\begin{array}{c}0.8 \mathrm{~m} \\
(20 \mathrm{~m})\end{array}$ & $\begin{array}{c}1.4 \mathrm{sec} \\
(7.0 \mathrm{sec})\end{array}$ & $\begin{array}{l}6 \mathrm{~cm} \\
(1.5 \mathrm{~m})\end{array}$ & $\begin{array}{l}2.88 \mathrm{~m} \\
(72.0 \mathrm{~m})\end{array}$ & $\begin{array}{l}2.182203 \\
(0.08727)\end{array}$ & 0.020839 \\
\hline 2 & $\begin{array}{c}0.8 \mathrm{~m} \\
(20 \mathrm{~m})\end{array}$ & $\begin{array}{c}1.4 \mathrm{sec} \\
(7.0 \mathrm{sec})\end{array}$ & $\begin{array}{c}9 \mathrm{~cm} \\
(2.25 \mathrm{~m})\end{array}$ & $\begin{array}{l}2.88 \mathrm{~m} \\
(72 \mathrm{~m})\end{array}$ & $\begin{array}{l}2.182203 \\
(0.08727)\end{array}$ & 0.031258 \\
\hline 3 & $\begin{array}{c}0.8 \mathrm{~m} \\
(20 \mathrm{~m})\end{array}$ & $\begin{array}{c}1.7 \mathrm{sec} \\
(8.5 \mathrm{sec})\end{array}$ & $\begin{array}{c}6 \mathrm{~cm} \\
(2.4 \mathrm{~m})\end{array}$ & $\begin{array}{l}3.88 \mathrm{~m} \\
(97 \mathrm{~m})\end{array}$ & $\begin{array}{l}1.678474 \\
(0.06477)\end{array}$ & 0.015456 \\
\hline 4 & $\begin{array}{c}0.8 \mathrm{~m} \\
(20 \mathrm{~m})\end{array}$ & $\begin{array}{c}1.7 \mathrm{sec} \\
(8.5 \mathrm{sec})\end{array}$ & $\begin{array}{c}8 \mathrm{~cm} \\
(2.0 \mathrm{~m})\end{array}$ & $\begin{array}{l}3.88 \mathrm{~m} \\
(97 \mathrm{~m})\end{array}$ & $\begin{array}{l}1.618474 \\
(0.06477)\end{array}$ & 0.020607 \\
\hline 5 & $\begin{array}{c}0.8 \mathrm{~m} \\
(20 \mathrm{~m})\end{array}$ & $\begin{array}{c}1.7 \mathrm{sec} \\
(8.5 \mathrm{sec})\end{array}$ & $\begin{array}{c}11 \mathrm{~cm} \\
(2.75 \mathrm{~m})\end{array}$ & $\begin{array}{l}3.88 \mathrm{~m} \\
(97 \mathrm{~m})\end{array}$ & $\begin{array}{l}1.618474 \\
(0.06477)\end{array}$ & 0.028335 \\
\hline 6 & $\begin{array}{c}0.8 \mathrm{~m} \\
(20 \mathrm{~m})\end{array}$ & $\begin{array}{c}2.0 \mathrm{sec} \\
(10 \mathrm{sec})\end{array}$ & $\begin{array}{c}6 \mathrm{~cm} \\
(2.4 \mathrm{~m})\end{array}$ & $\begin{array}{c}4.85 \mathrm{~m} \\
(121.24 \mathrm{~m})\end{array}$ & $\begin{array}{l}1.295642 \\
(0.05182)\end{array}$ & 0.012372 \\
\hline 7 & $\begin{array}{c}0.8 \mathrm{~m} \\
(20 \mathrm{~m})\end{array}$ & $\begin{array}{c}2.0 \mathrm{sec} \\
(10 \mathrm{sec})\end{array}$ & $\begin{array}{c}8 \mathrm{~cm} \\
(2.0 \mathrm{~m})\end{array}$ & $\begin{array}{c}4.85 \mathrm{~m} \\
(121.24 \mathrm{~m})\end{array}$ & $\begin{array}{l}1.295642 \\
(0.05182)\end{array}$ & 0.016497 \\
\hline 8 & $\begin{array}{c}0.8 \mathrm{~m} \\
(20 \mathrm{~m})\end{array}$ & $\begin{array}{c}2.0 \mathrm{sec} \\
(10 \mathrm{sec})\end{array}$ & $\begin{array}{c}11 \mathrm{~cm} \\
(2.75 \mathrm{~m})\end{array}$ & $\begin{array}{c}4.85 \mathrm{~m} \\
(121.24 \mathrm{~m})\end{array}$ & $\begin{array}{l}1.295642 \\
(0.05182)\end{array}$ & 0.022683 \\
\hline
\end{tabular}

Digits in ( ) are parameters for the prototype

liquid filled in the tube and initial pre-tension force must be taken into accounts in the experimental test. The testing wave conditions include the wave-height, water-depth and the period of the wave. The detailed wave conditions in the testing sequence are obtained from the dimensional analysis and the consideration of the testing limit of the water-tank, which are shown in Table 1. During the experimental tests three groups of tests were carried out, namely: (1) the variation of wave period and wave-height, (2) the variation of initial draught of the UWTLCD-TLP and (3) the variation of the liquid-length in the tube. In each group of test, two sets of testing model-platform were tested, namely, model-platform without installation of UWTLCD device and the other one with UWTLCD. All conditions were set the same between these two model platform systems except for the installation

Table 2 Testing sequences and related parameters

\begin{tabular}{|c|c|c|c|c|c|c|c|}
\hline \multirow{2}{*}{$\begin{array}{l}\text { Testing } \\
\text { groups }\end{array}$} & \multirow{2}{*}{$\begin{array}{l}\text { Observation } \\
\text { parameters }\end{array}$} & \multicolumn{2}{|c|}{ Wave conditions } & \multicolumn{2}{|c|}{ Tether and draught } & \multicolumn{2}{|c|}{ 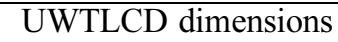 } \\
\hline & & Period & Wave height & Draught & Pretension force & Liquid length & Mass \\
\hline \multirow{5}{*}{1} & \multirow{3}{*}{$\begin{array}{l}\text { Period and } \\
\text { wave-height }\end{array}$} & $1.7 \mathrm{sec}$ & $11 \mathrm{~cm}$ & -- & $1.2 \mathrm{~kg}(11.77 \mathrm{~N})$ & $90 \mathrm{~cm}$ & $11.8 \mathrm{~kg}$ \\
\hline & & $2.0 \mathrm{sec}$ & $8 \mathrm{~cm}$ & -- & $1.2 \mathrm{~kg}(11.77 \mathrm{~N})$ & $90 \mathrm{~cm}$ & $11.8 \mathrm{~kg}$ \\
\hline & & $2.0 \mathrm{sec}$ & $11 \mathrm{~cm}$ & -- & $1.2 \mathrm{~kg}(11.77 \mathrm{~N})$ & $90 \mathrm{~cm}$ & $11.8 \mathrm{~kg}$ \\
\hline & \multirow{2}{*}{$\begin{array}{c}\text { Amplitude } \\
\text { variation }\end{array}$} & $1.7 \mathrm{sec}$ & $6,8,11 \mathrm{~cm}$ & -- & $1.2 \mathrm{~kg}(11.77 \mathrm{~N})$ & $90 \mathrm{~cm}$ & $11.8 \mathrm{~kg}$ \\
\hline & & $2.0 \mathrm{sec}$ & $6,8,11 \mathrm{~cm}$ & -- & $1.2 \mathrm{~kg}(11.77 \mathrm{~N})$ & $90 \mathrm{~cm}$ & $11.8 \mathrm{~kg}$ \\
\hline \multirow{3}{*}{2} & \multirow{3}{*}{$\begin{array}{l}\text { Draught and } \\
\text { tether forces }\end{array}$} & \multirow{3}{*}{$2.0 \mathrm{sec}$} & \multirow{3}{*}{$6 \mathrm{~cm}$} & $55 \mathrm{~cm}$ & $0.7 \mathrm{~kg}(6.87 \mathrm{~N})$ & \multirow{3}{*}{$90 \mathrm{~cm}$} & \multirow{3}{*}{$11.8 \mathrm{~kg}$} \\
\hline & & & & $58 \mathrm{~cm}$ & $1.1 \mathrm{~kg}(10.79 \mathrm{~N})$ & & \\
\hline & & & & $60 \mathrm{~cm}$ & $1.4 \mathrm{~kg}(13.73 \mathrm{~N})$ & & \\
\hline \multirow{3}{*}{3} & \multirow{3}{*}{$\begin{array}{l}\text { Length of liquid } \\
\text { column }\end{array}$} & \multirow{3}{*}{$2.0 \mathrm{sec}$} & \multirow{3}{*}{$6 \mathrm{~cm}$} & \multirow{3}{*}{--} & \multirow{3}{*}{--} & $90 \mathrm{~cm}$ & $11.8 \mathrm{~kg}$ \\
\hline & & & & & & $100 \mathrm{~cm}$ & $13.8 \mathrm{~kg}$ \\
\hline & & & & & & $110 \mathrm{~cm}$ & $15.8 \mathrm{~kg}$ \\
\hline
\end{tabular}


of UWTLCD device. The testing sequences of the model corresponding to the wave conditions and structural parameters are shown in Table 2

\section{Experimental results and discussion}

The typical experimental testing results for both time-domain responses and frequency response spectrum are presented. The time variation of pre-tension force is also presented in this section. The mitigation effect of the responses in terms of the reduction ratio in the responses of surge, heave and pitch is estimated and discussed.

Since a paper focused on the theoretical study has been thoroughly presented (Lee and Won 2006) and the theoretical formulation of this paper was adapted and revised in minor parts basically related to the constricted cross-section of the horizontal tube and the underwater application, a verification for the formulation presented in this study will be simple. As shown in Fig. 5(a) and (b) are frequency responses of the model platform in surge direction, first one the experimental result

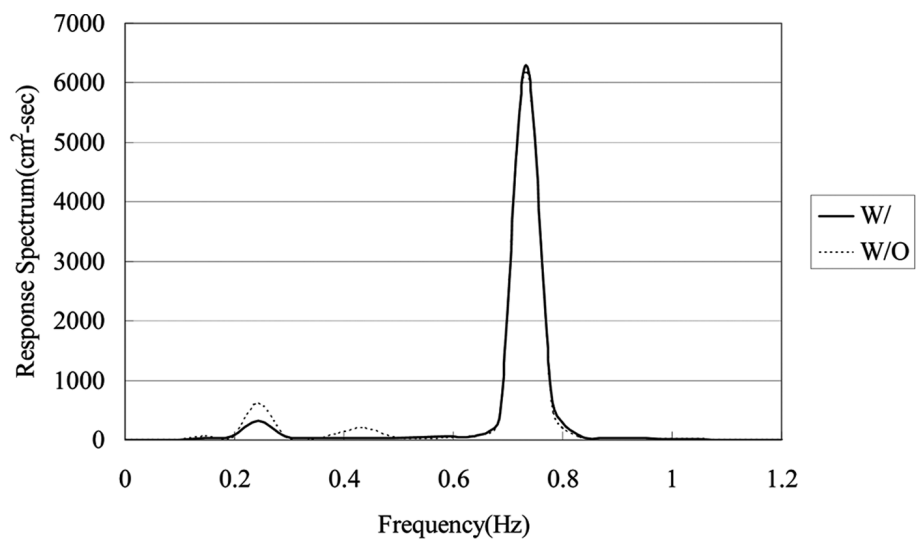

(a) Experimental results

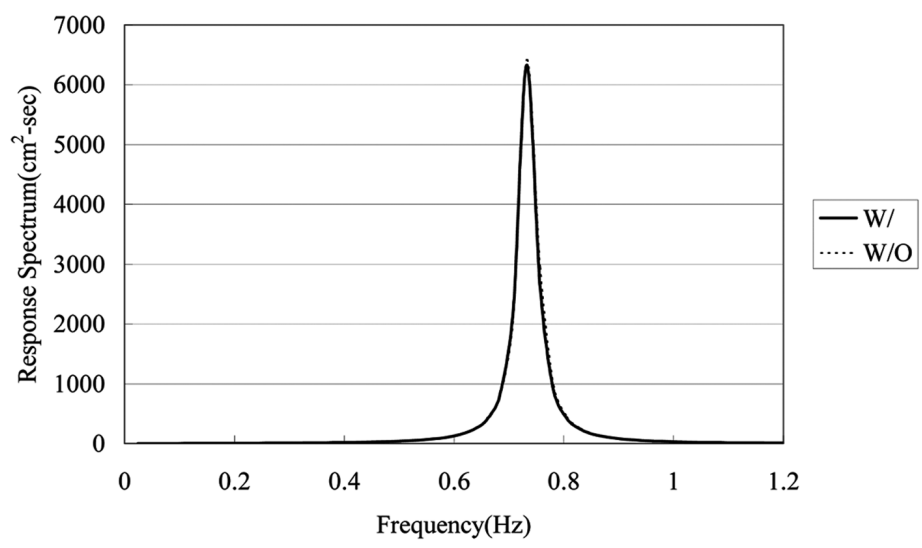

(b) Theoretical results

Fig. 5 Comparison of theoretical and experimental results $(T=1.4 \mathrm{sec}, h=9 \mathrm{~cm})$ 


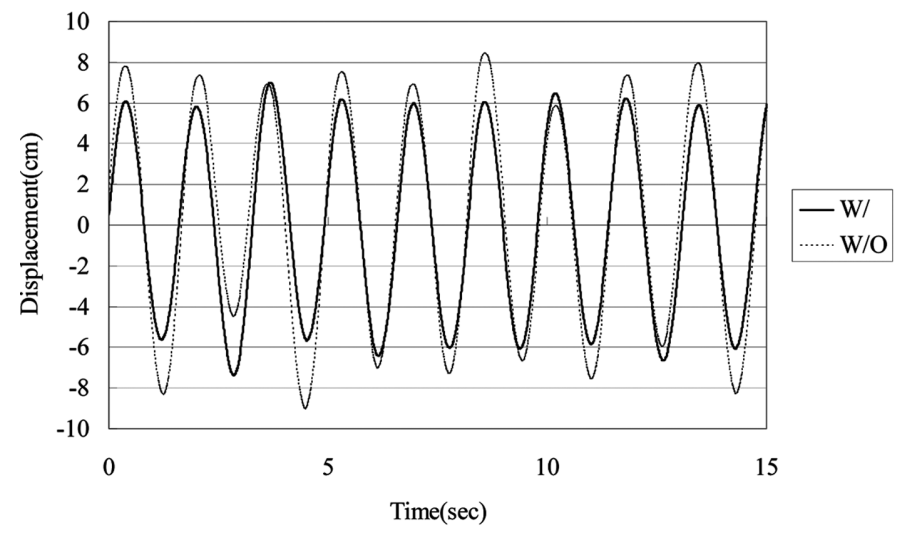

(a) Surge motion

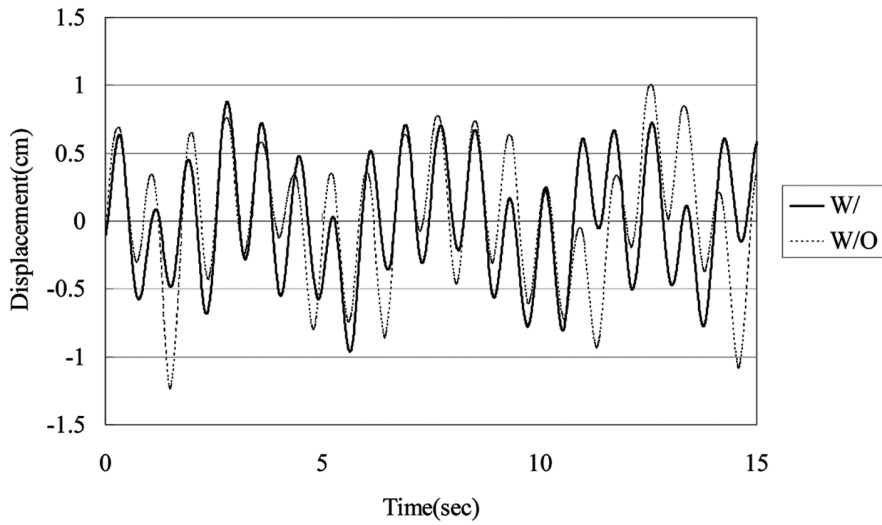

(b) Heave motion

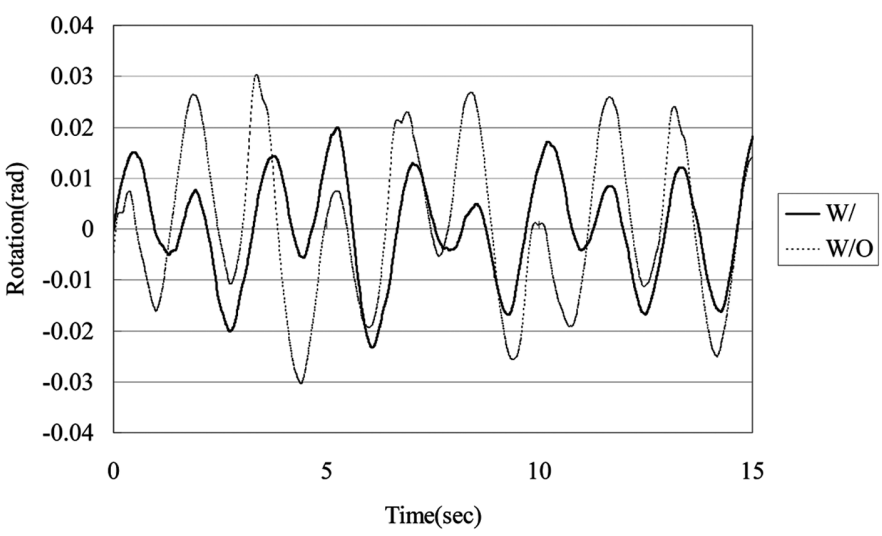

(c) Pitch motion

Fig. 6 Response comparison in time domain under conditions: $T=1.7 \mathrm{sec}, h=11 \mathrm{~cm}$

and the second the theoretical result for a wave condition of 1.4 seconds period and $9 \mathrm{~cm}$ height. A very good agreement between the experimental and theoretical results was found in terms of both the response amplitude and the dominant frequency. However, some minor responses in the experimental 
Experimental study on the vibration mitigation of offshore tension leg platform system with UWTLCD 83

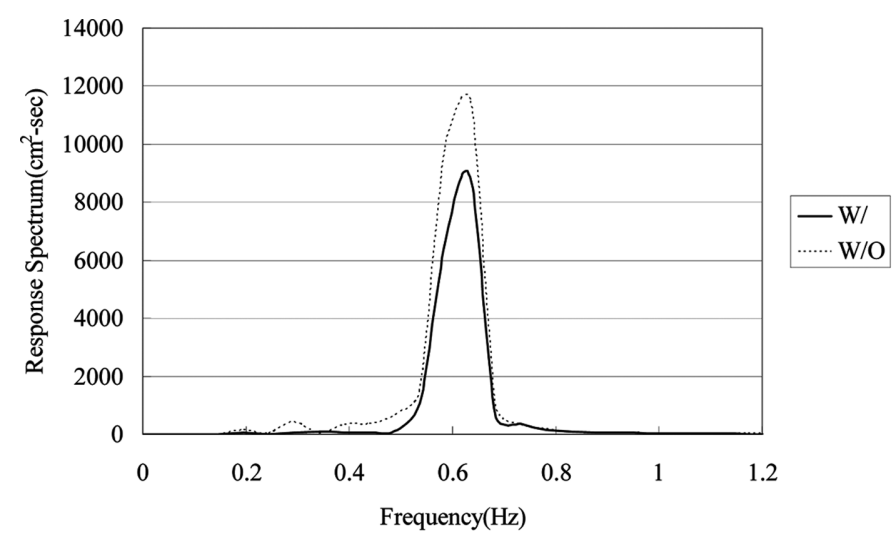

(a) Surge motion

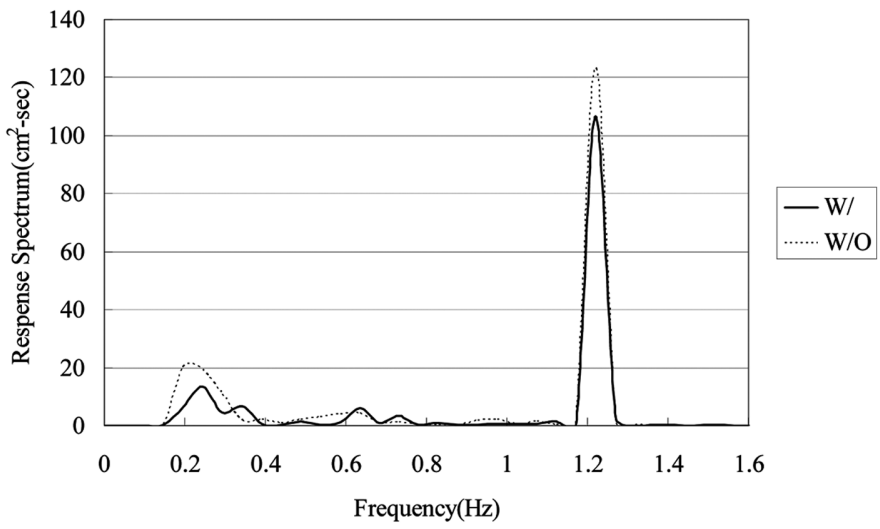

(b) Heave motion

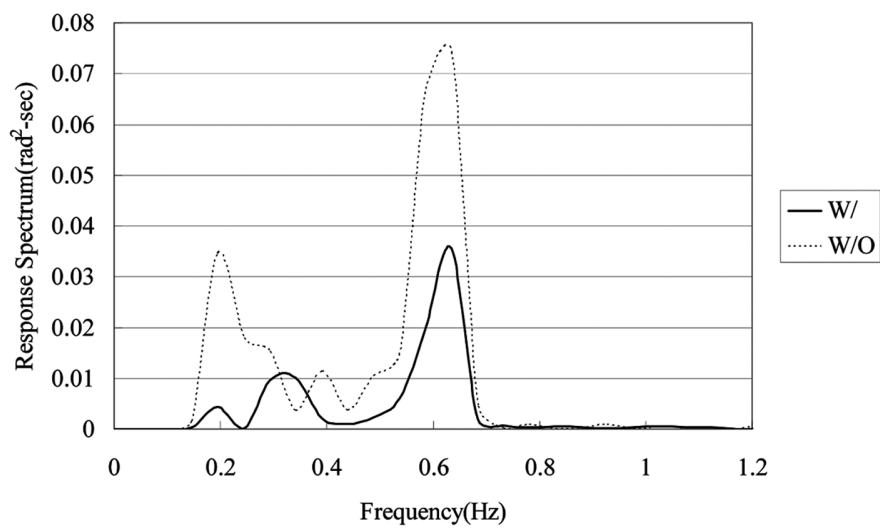

(c) Pitch motion

Fig. 7 Response comparison in frequency domain under conditions: $T=1.7 \mathrm{sec}, h=11 \mathrm{~cm}$

results scattered in the lower frequency range are not possibly calculated from theoretical formulation due to a linear simplification of the theorem. 


\subsection{Typical response in both time domain and frequency domain}

For the testing case of 1.7 seconds period and $11 \mathrm{~cm}$ height waves, Figs. 6(a), (b) and (c) show the comparison of typical responses of the platform model in time domain, where the surge, heave and pitch responses of the platform are mitigated when the UWTLCD system is installed compared to the ones without installation of UWTLCD device. The corresponding response spectrums also indicate a similar suppression effect as shown in Figs. 7(a), (b) and (c). It shows that for the surge, heave and pitch motion the vibration suppression effect is more significant in surge and pitch motions.

For the testing case of 2 second period and $8 \mathrm{~cm}$ height waves, Figs. 8(a), (b) and (c) also show the comparison of typical responses of the platform model in, where all responses of the platform aresignificantly mitigated when the UWTLCD system is installed. The corresponding response spectrums also indicate a similar mitigation effect as shown in Figs. 9(a), (b) and (c). Fig. 10(a) to (c) show a similar comparison of the time domain responses of the platform with and without installation of the UWTLCD system while the applied wave has same period but a higher wave-height of 11 $\mathrm{cm}$. As indicated in the response spectrum in Figs. 11(a), (b) and (c), and comparing with Fig. 9, the reduction effect for the responses in surge and pitch motion is better for $h=11 \mathrm{~cm}$ than $h=8 \mathrm{~cm}$. For the heave motions, UWTLCD seems to work better in the lower frequency range than in the higher frequency when the applied wave has larger wave-height.

\subsection{Mitigation effect on the amplitude of the response}

The effect of the mitigation for the response amplitude of the model platform was estimated as a ratio to the response without installation of UWTLCD in terms of both the average and maximum amplitude measured in the experimental tests. For the applied waves of 1.7 second period, Figs. 12(a), (b) and (c) show the mitigation effect corresponding to surge, heave and pitch motions when the wave-height varied as $6 \mathrm{~cm}, 8 \mathrm{~cm}$ and $11 \mathrm{~cm}$ in the tests. Clearly, for the surge motion as indicated in Fig. 12(a) the reduction on the average response amplitude can be up to $25 \%$ while the reduction on the maximum amplitude can be up to $30 \%$. For the reduction on the heave motion as shown in Fig. 12(b), even though the overall heave motion is reduced up to $16 \%$ as indicated in average response, during the test of $6 \mathrm{~cm}$ wave-height the maximum response seems to be amplified a little by the UWTLCD. For the pitch motion the reduction effect is better such as the reduction ratio for both the average and maximum response could reach up to about $50 \%$ than the original ones.

For the applied waves of 2.0 second period, Figs. 13(a), (b) and (c) also show the mitigation effect corresponding to surge, heave and pitch motions when the wave-height varied as $6 \mathrm{~cm}, 8 \mathrm{~cm}$ and $11 \mathrm{~cm}$ in the test. Again, for the surge motion as indicated in Fig. 13(a) the reduction on the average response amplitude is up to $32 \%$ while the reduction on the maximum amplitude can be up to $38 \%$. For the reduction on the heave motion as indicated in Fig. 13(b), it is also obviously observed that the reduction ratio for the average response could reach $39 \%$ for the case of wave-height of $6 \mathrm{~cm}$. A similar reduction effect was also observed for the pitch motion as indicated in Fig. 13(c) in both of the average and maximum responses. Corresponding to the increase of the period,the mitigation effect from the installed UWTLCD seems to become better except for pitch motion for wave-height $h=6 \mathrm{~cm}$. 
Experimental study on the vibration mitigation of offshore tension leg platform system with UWTLCD 85

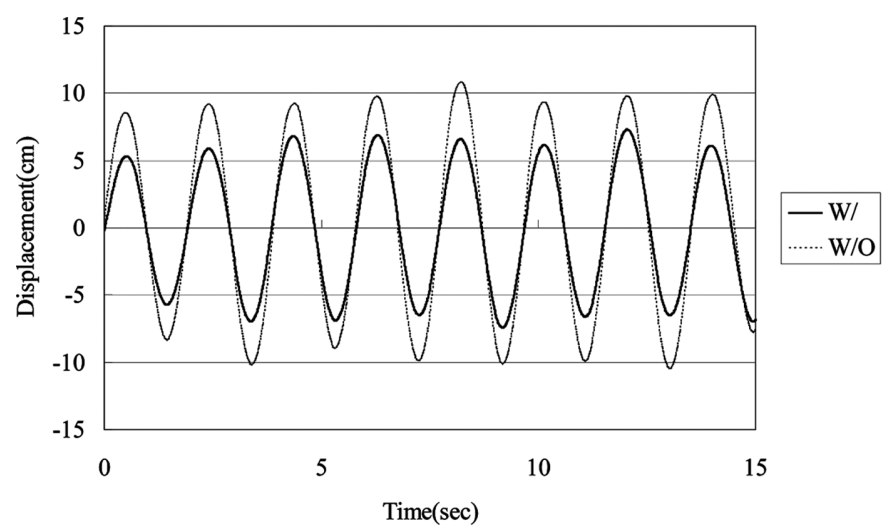

(a) Surge motion

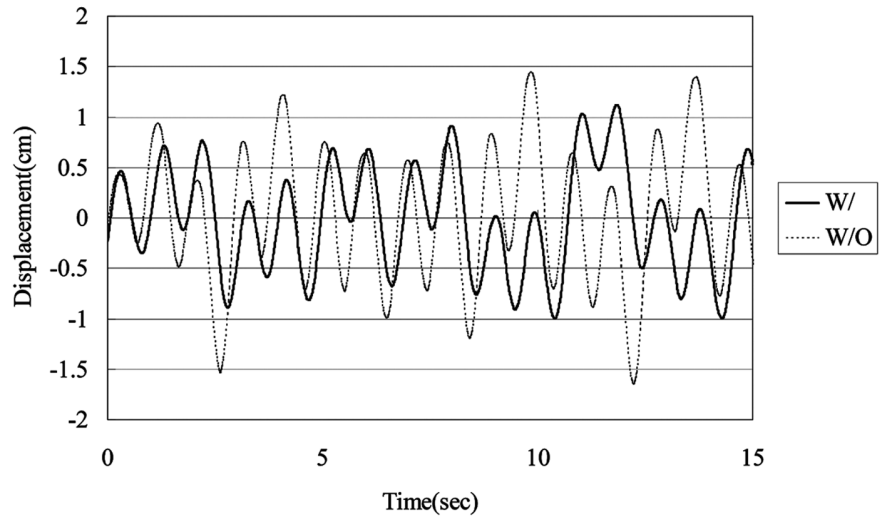

(b) Heave motion

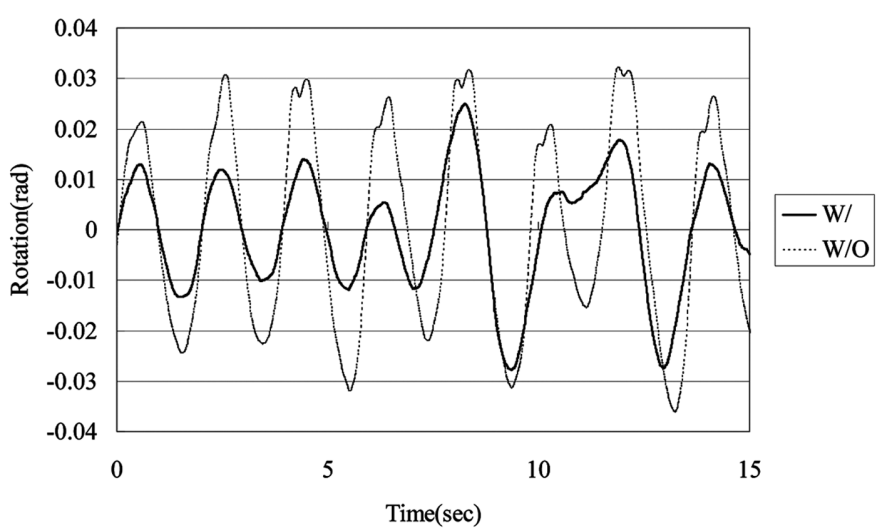

(c) Pitch motion

Fig. 8 Response comparison of platform in time domain under conditions: $T=2.0 \mathrm{sec}, h=8 \mathrm{~cm}$

\subsection{Mitigation effect on total response of the system}

The response and variation for the tensile force of the tethers were measured for the safety sake 


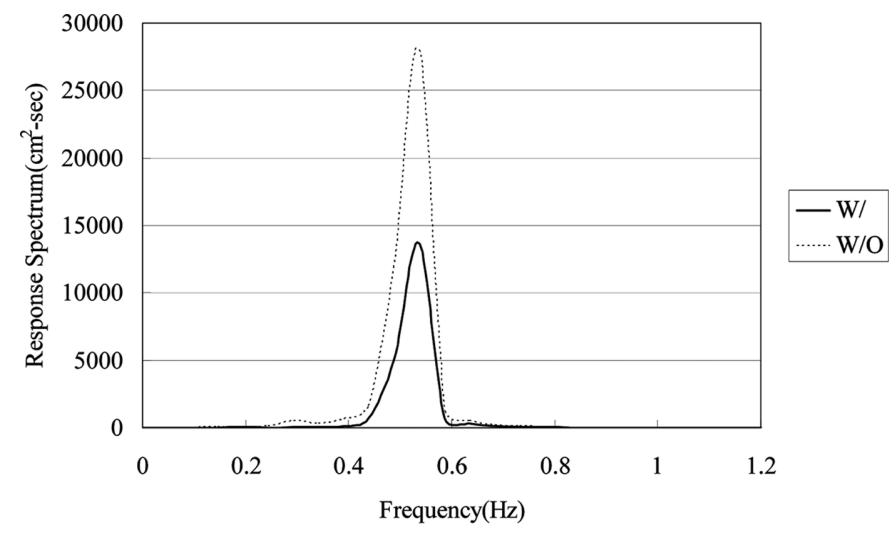

(a) Surge motion

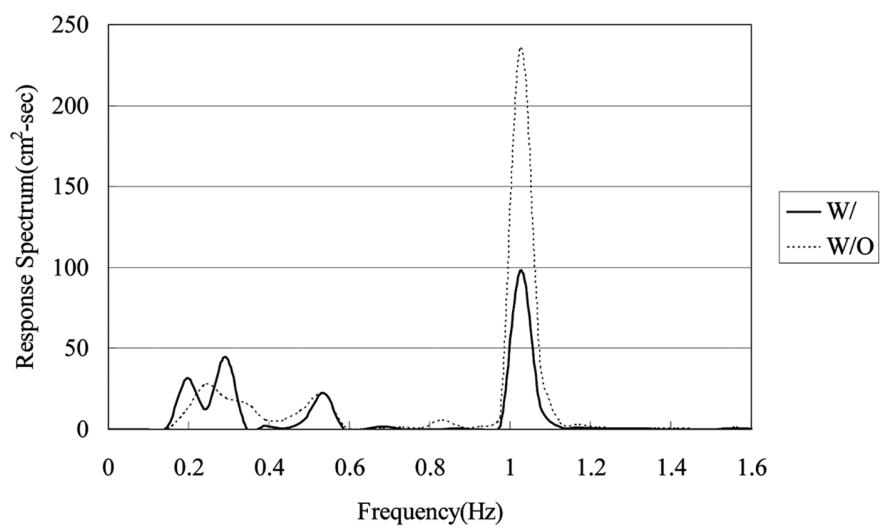

(b) Heave motion

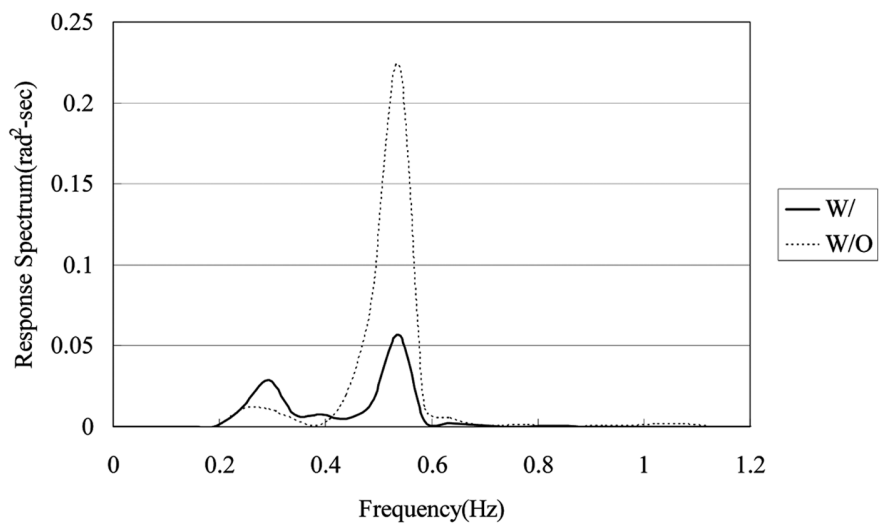

(c) Pitch motion

Fig. 9 Response comparison in frequency domain under conditions: $T=2.0 \mathrm{sec}, h=8 \mathrm{~cm}$

that fatigue-failure occurred to any single tether of the mooring system may cause serious damage for the whole offshore platform system. Figs. 14(a), (b) and (c) show the measured variation of the 


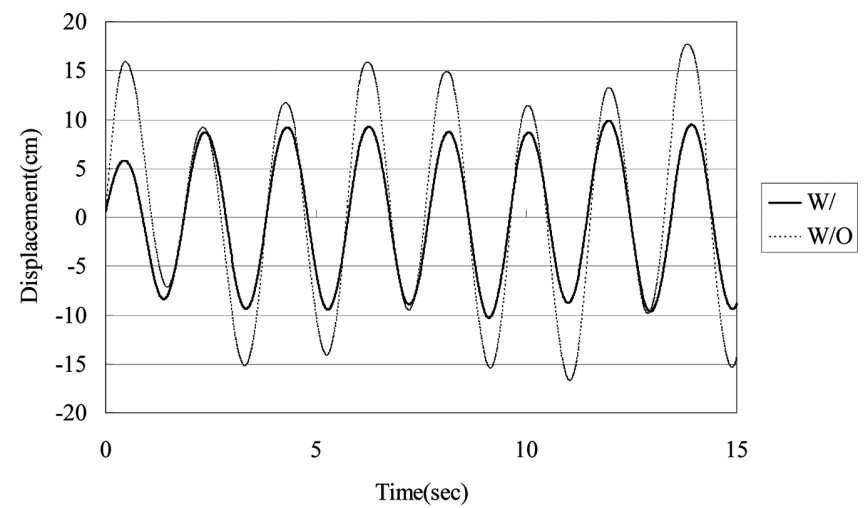

(a) Surge motion

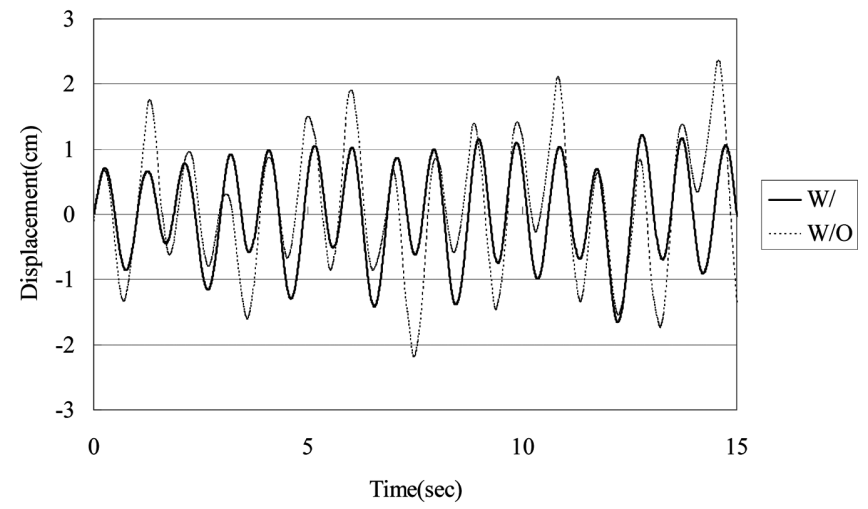

(b) Heave motion

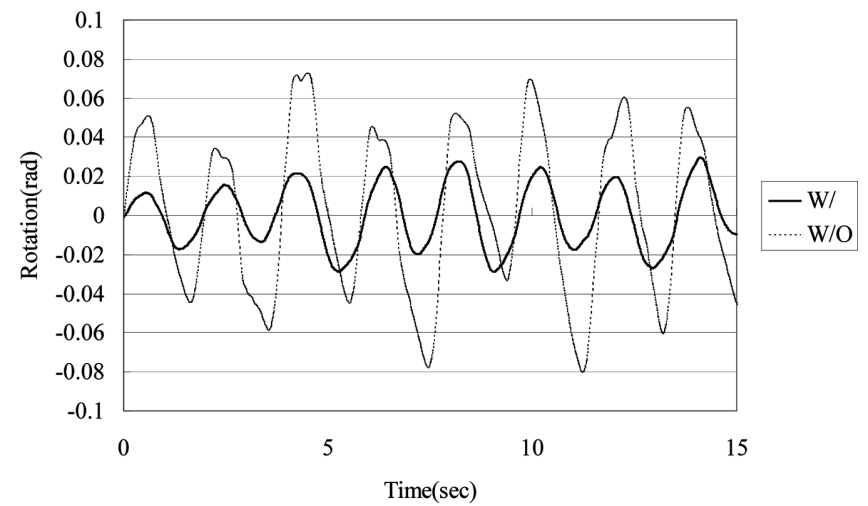

(c) Pitch motion

Fig. 10 Response comparison of platform in time domain under conditions: $T=2.0 \mathrm{sec}, h=11 \mathrm{~cm}$

tensile forces in the tethers during the test when the model platform is subjected to 1.7 second waves of wave-height ranged from $6 \mathrm{~cm}$ to $11 \mathrm{~cm}$ alternately. It shows the reduction on the tensile forces when the platform is equipped with UWTLCD system. It indicates that the material may last longer when the offshore platform is subjected to similar wave condition since the tethers are less stressed. 


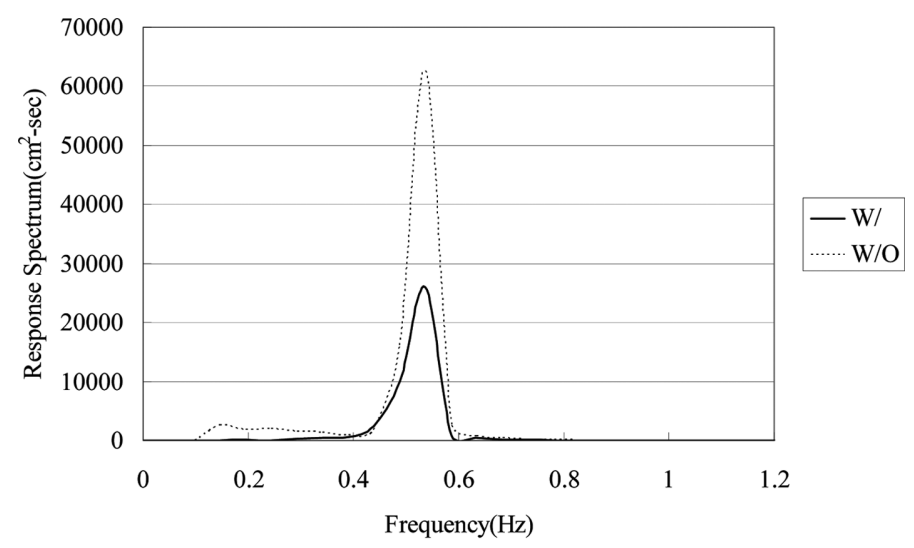

(a) Surge motion

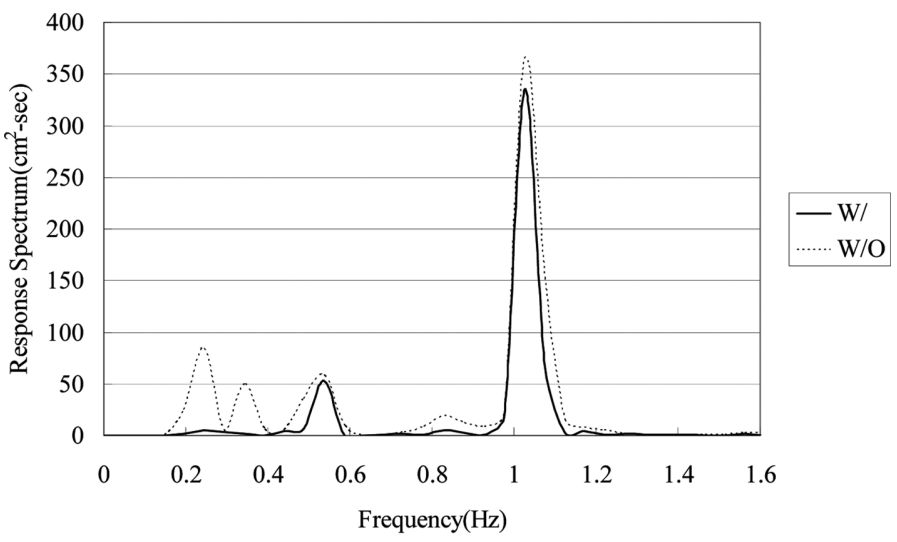

(b) Heave motion

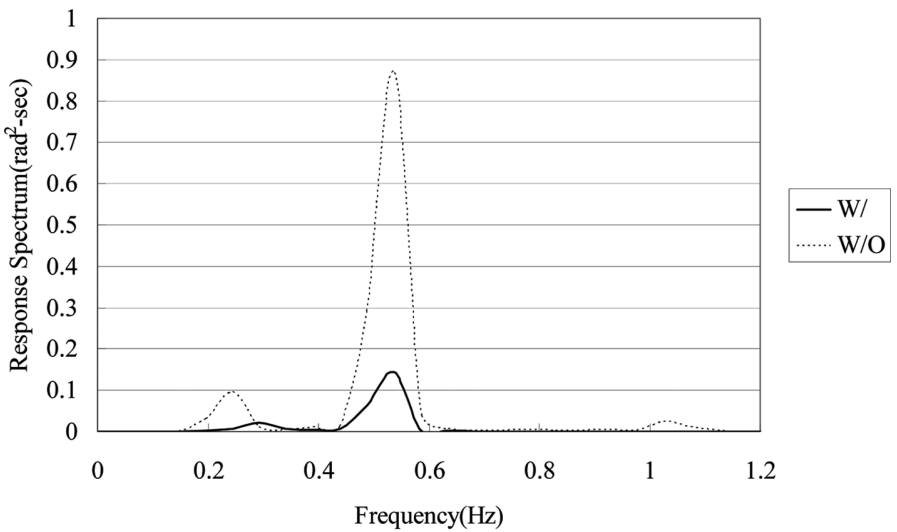

(c) Pitch motion

Fig. 11 Response comparison in frequency domain under conditions: $T=2.0 \mathrm{sec}, h=11 \mathrm{~cm}$

Because the pre-tensioned tether is the only component providing resistance to the motion of the platform including surge, heave and pitch, the reduction in tensile force may represent an overall 


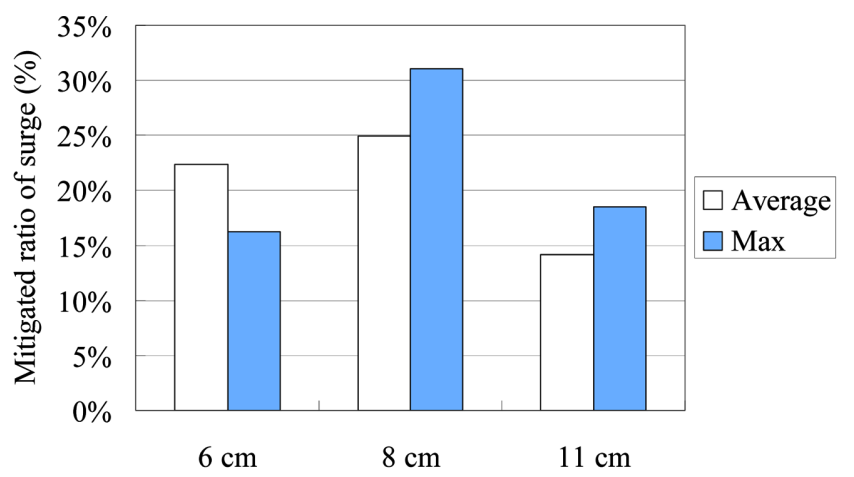

(a) Surge motion

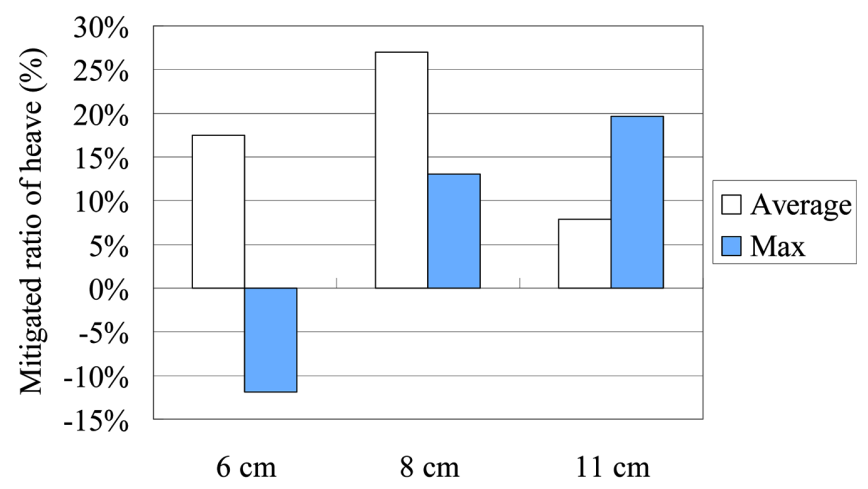

(b) Heave motion

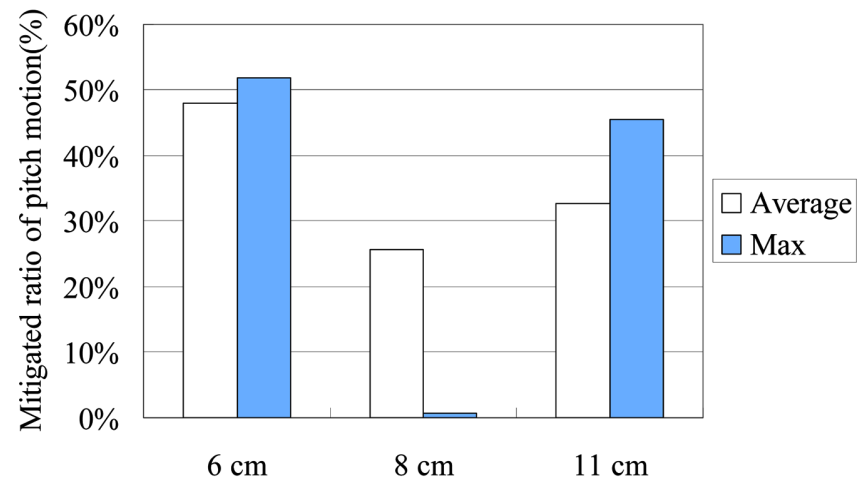

(c) Pitch motion

Fig. 12 Response amplitude reduction ratio under conditions: $T=1.7 \mathrm{sec}, h=6,8,11 \mathrm{~cm}$

effect of the mitigation. By comparing Fig. 14 with Fig. 15, which shows the surge motions of the model platform measured at the same time during the test subjected to the same wave conditions (1.7 sec. with $6,8,11 \mathrm{~cm}$ wave-height), it can be seen that the mitigation in the tensile force (Fig. 14) is much more effective than the mitigation in the surge motion. It is because the tether force account for all motions of the platform besides the surge motion and therefore, the mitigation effect reflected in the tension of the tether is more significant than surge motion. 


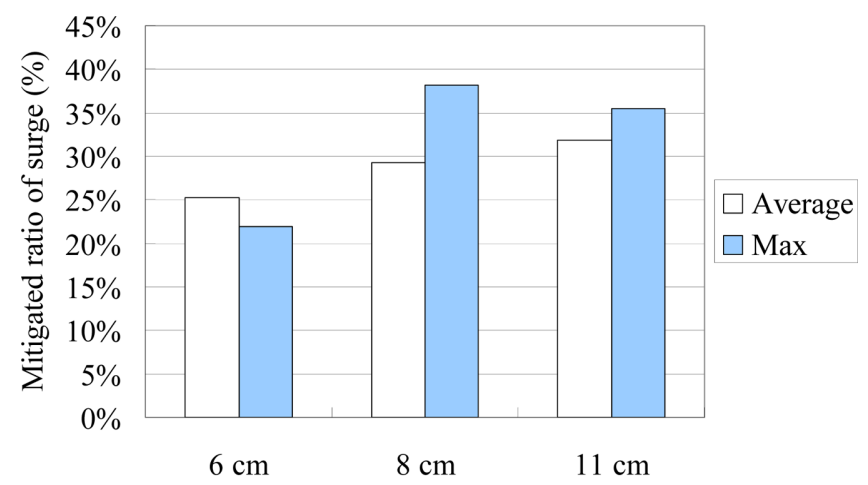

(a) Surge motion

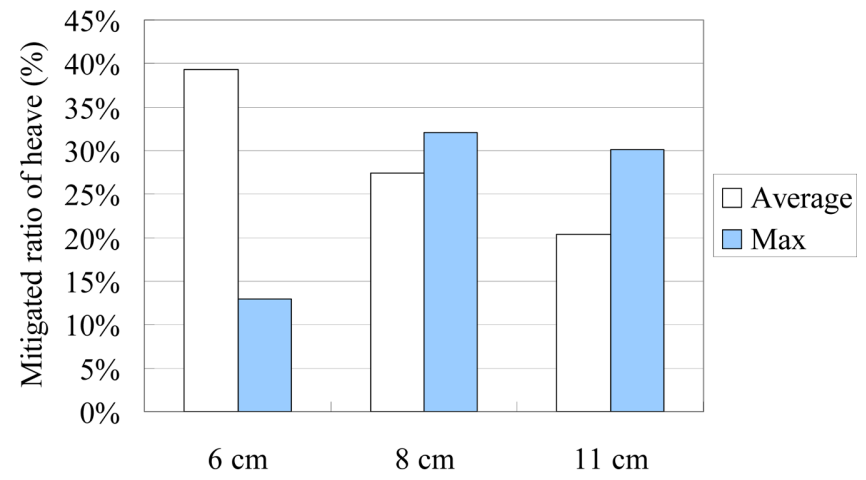

(b) Heave motion

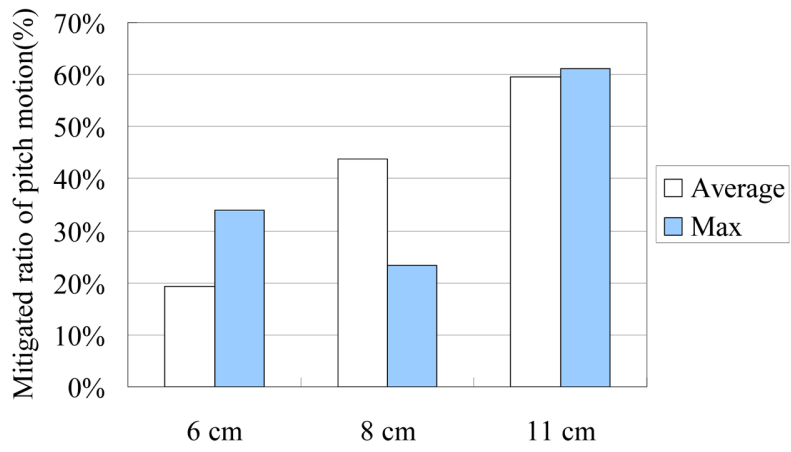

(c) Pitch motion

Fig. 13 Response amplitude reduction ratio under conditions: $T=2.0 \mathrm{sec}, h=6,8,11 \mathrm{~cm}$

\subsection{Effect on the variation of the pretension force}

Once the mass and the dimension of the floating body are set, the pretension force can be adjusted according to the draught of the pontoons. Due to the limit of the water depth, the variation of the initial pretension force corresponding to the initial draught of the pontoon was carefully tuned during the test. The testing wave condition is set as 2 second period and $6 \mathrm{~cm}$ wave-height while the draught of the TLP is varied as $55 \mathrm{~cm}, 58 \mathrm{~cm}$ and $60 \mathrm{~cm}$. Figs. 16(a), (b) and (c) show the comparison 
Experimental study on the vibration mitigation of offshore tension leg platform system with UWTLCD 91

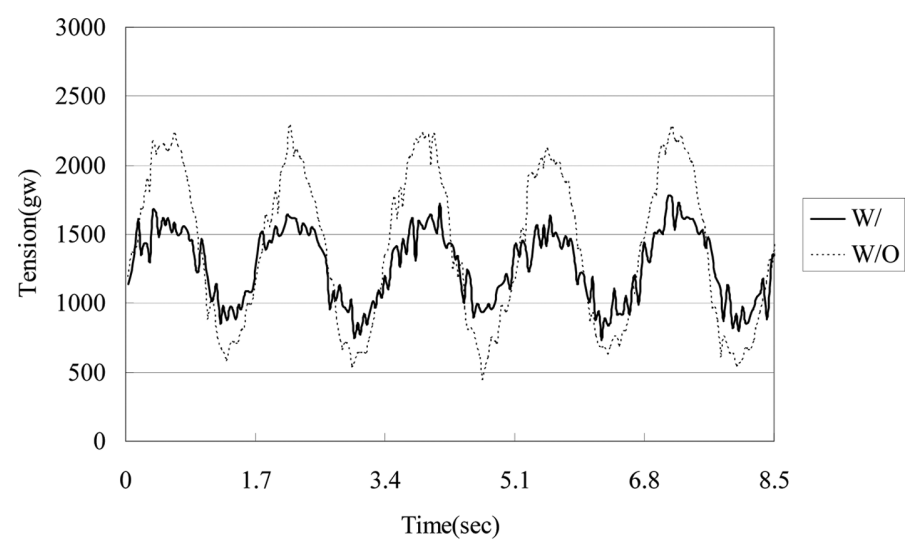

(a) Wave condition: $\mathrm{T}=1.7 \mathrm{sec}, \mathrm{h}=6 \mathrm{~cm}$

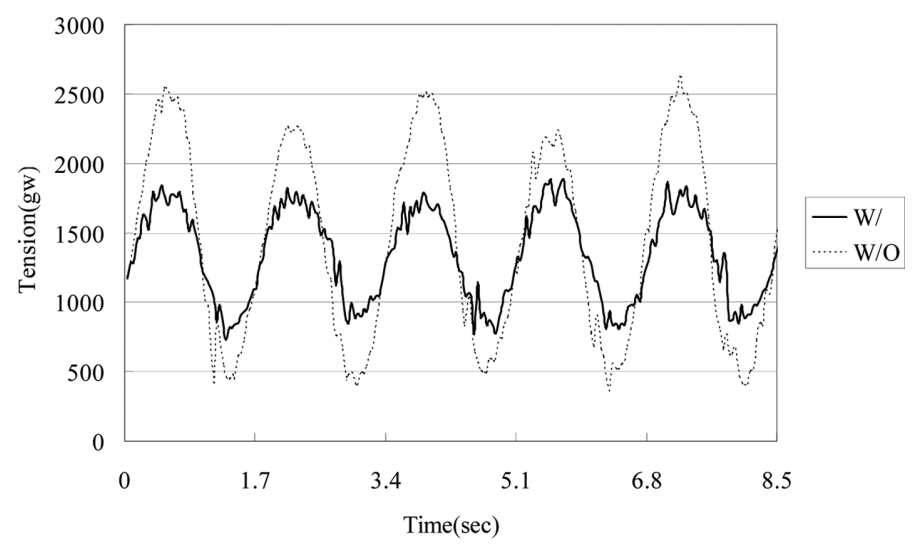

(b) Wave condition: $\mathrm{T}=1.7 \mathrm{sec}, \mathrm{h}=8 \mathrm{~cm}$

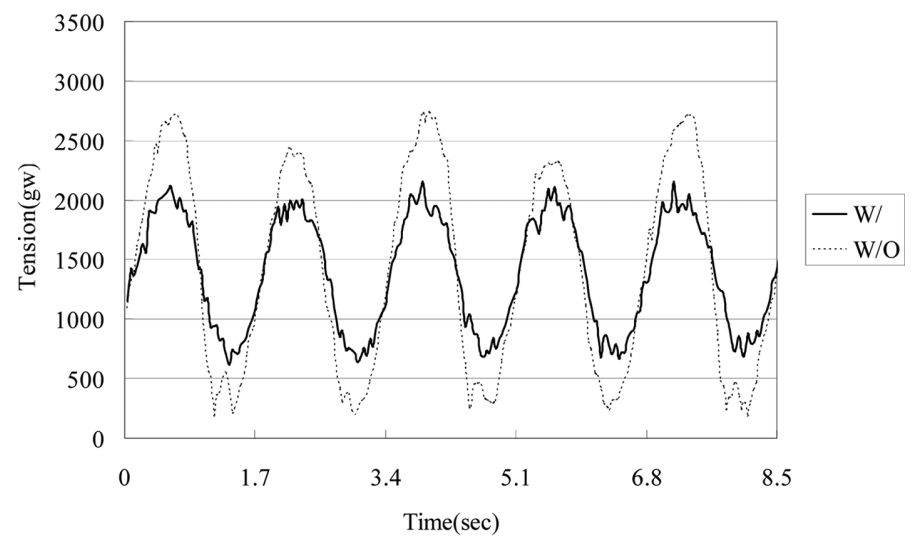

(c) Wave condition: $\mathrm{T}=1.7 \mathrm{sec}, \mathrm{h}=11 \mathrm{~cm}$

Fig. 14 Variation of tension force corresponding to various wave heights

of typical responses in the surge motion for the platform model in time domain corresponding to variations of the TLP draught. It can be seen that the variation of the draught does not affect much 


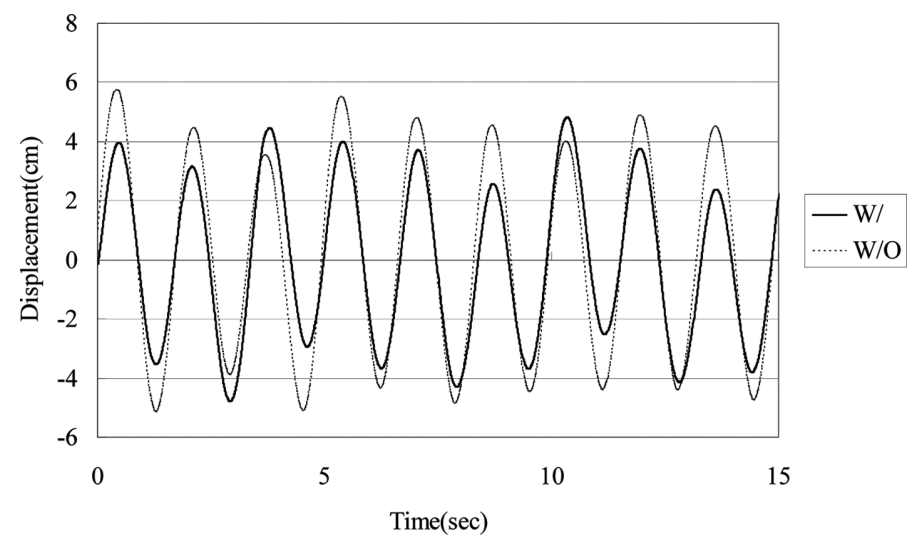

(a) Wave conditions: $\mathrm{T}=1.7 \mathrm{sec}, \mathrm{h}=6 \mathrm{~cm}$

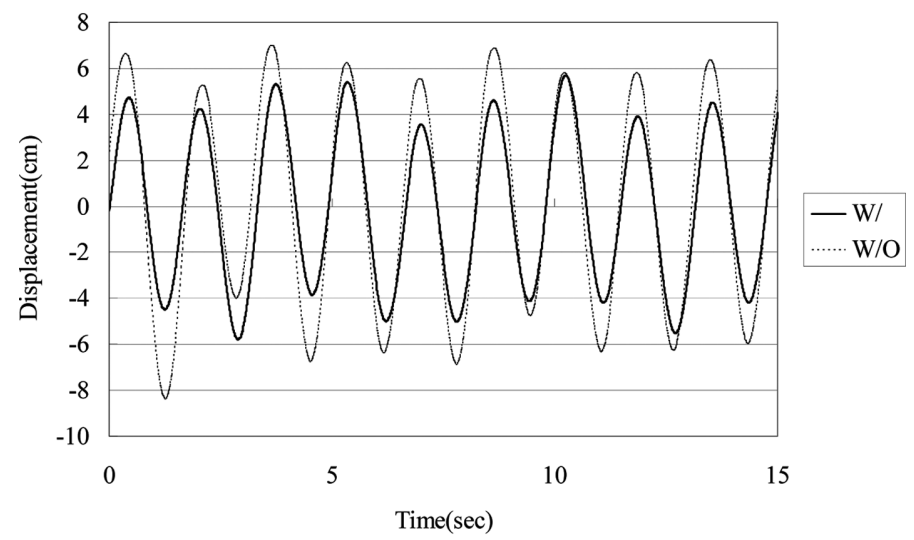

(b) Wave conditions: $\mathrm{T}=1.7 \mathrm{sec}, \mathrm{h}=8 \mathrm{~cm}$

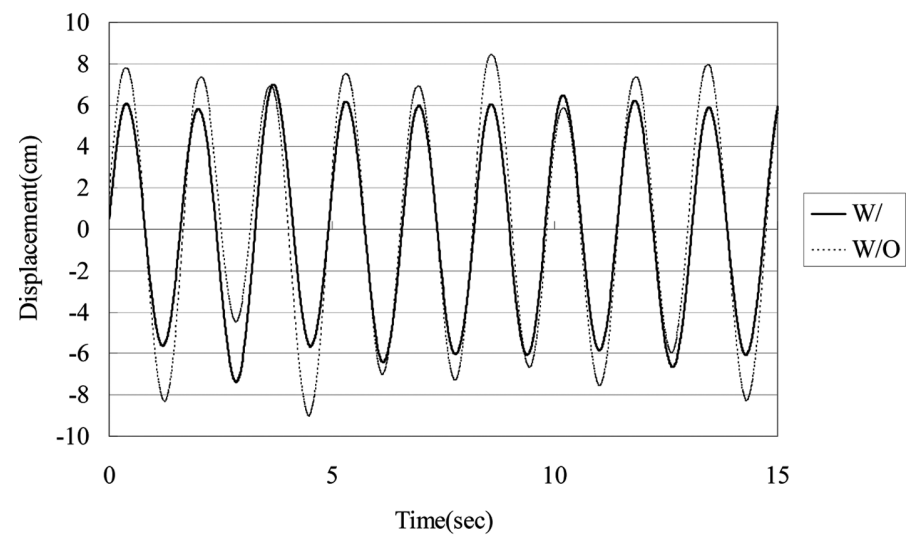

(c) Wave conditions: $\mathrm{T}=1.7 \mathrm{sec}, \mathrm{h}=11 \mathrm{~cm}$

Fig. 15 Comparison of surge response corresponding to various wave-heights

the reduction of the surge responses in these three cases. All responses were well mitigated by the UWTLCD device at a ratio of about $40 \%$. 
Experimental study on the vibration mitigation of offshore tension leg platform system with UWTLCD 93

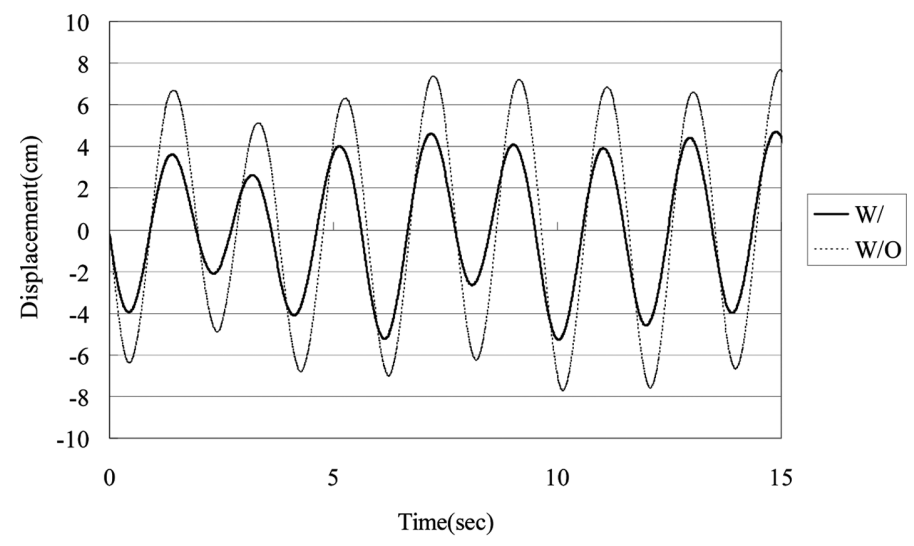

(a) Surge motion of $55 \mathrm{~cm}$ draught

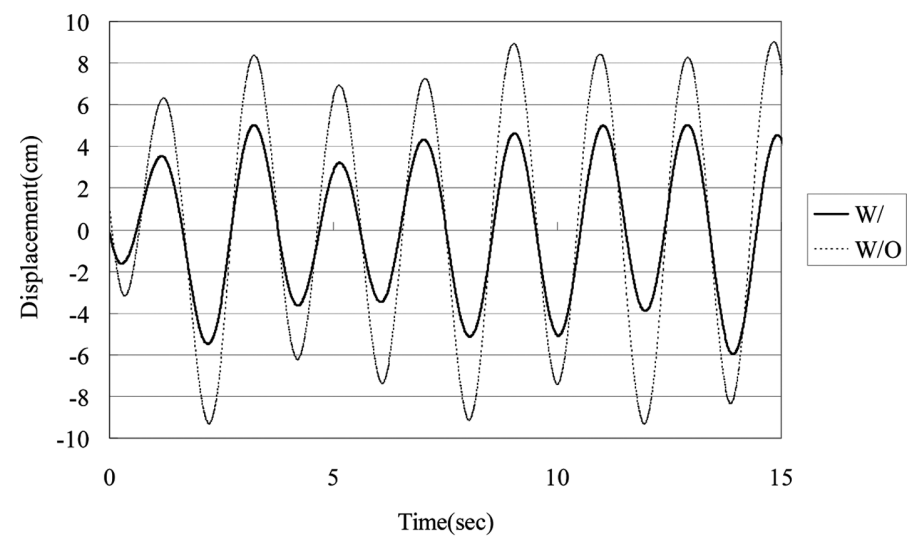

(b) Surge motion of $58 \mathrm{~cm}$ draught

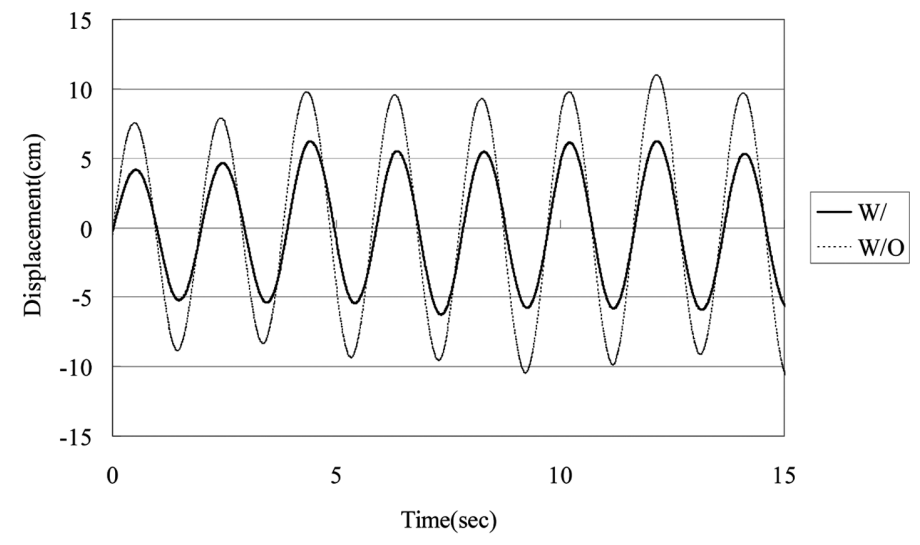

(c) Surge motion of $60 \mathrm{~cm}$ draught

Fig. 16 Comparison of surge response corresponding to various draughts $(T=2 \mathrm{sec}, h=6 \mathrm{~cm})$

Figs. 17, 18 and 19 show comparisons of typical frequency responses in surge, heave and pitch motions while the wave conditions remained and draughts of the UWTLCD-TLP were varied as 55 


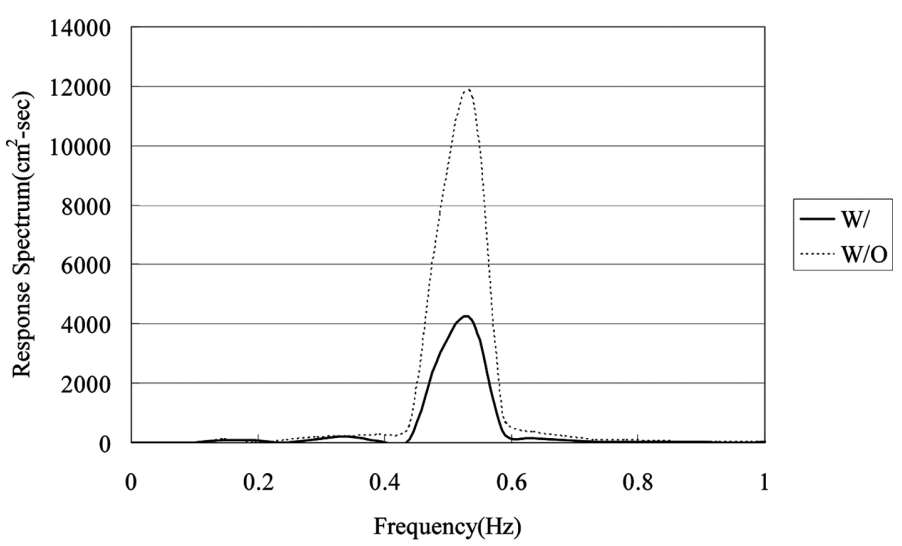

(a) Surge motion of $55 \mathrm{~cm}$ draught

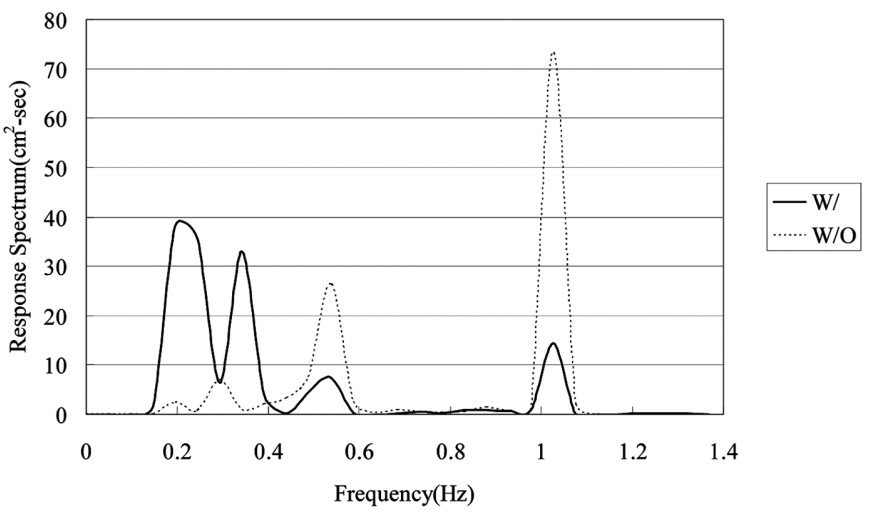

(b) Heave motion of $55 \mathrm{~cm}$ draught

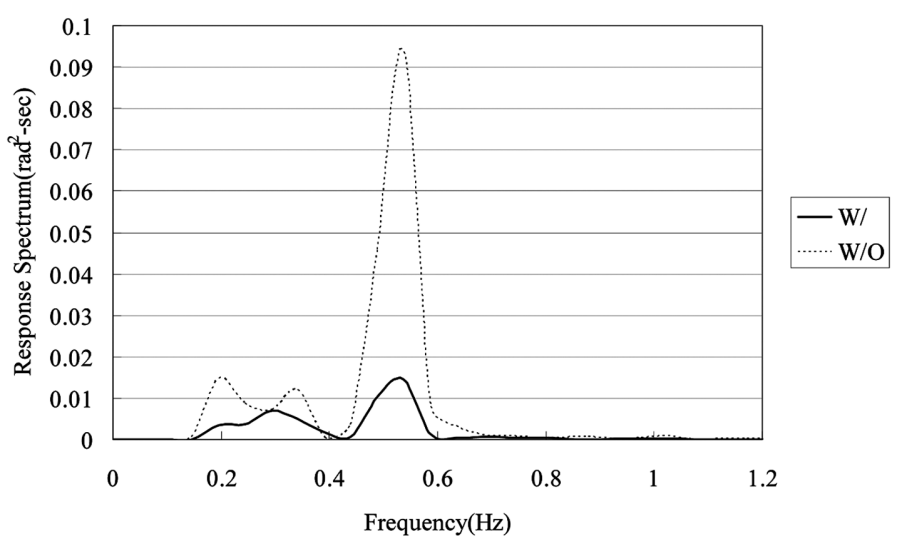

(c) Pitch motion of $55 \mathrm{~cm}$ draught

Fig. 17 Comparison of frequency response for $55 \mathrm{~cm}$ draught $(T=2 \mathrm{sec}, h=6 \mathrm{~cm})$

$\mathrm{cm}, 58$ and $60 \mathrm{~cm}$, respectively. For the surge motion observed from part (a) of these three figures, also as indicated in time domain responses in Fig. 16, the mitigation effect is significantly presented in both time and frequency responses. The natural period is about 1.9 seconds for the surge response, very close to the two seconds period of the exerting waves. However, as observed from 
Experimental study on the vibration mitigation of offshore tension leg platform system with UWTLCD 95

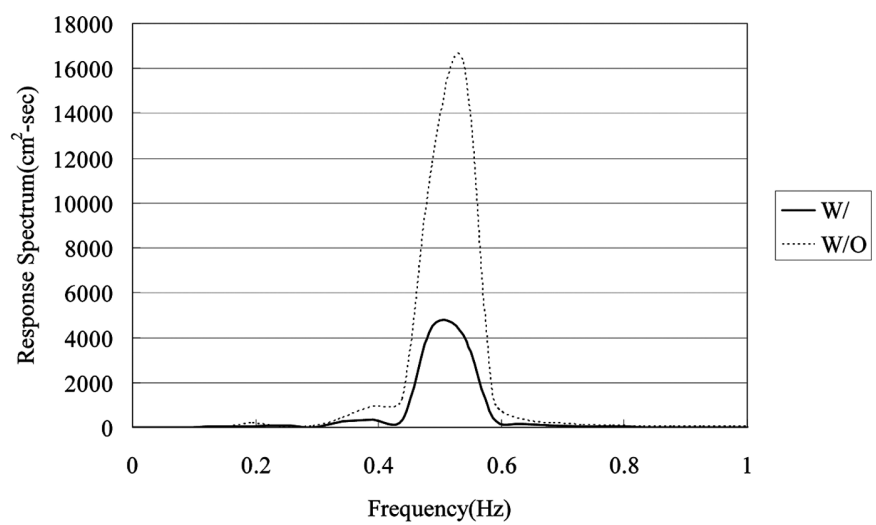

(a) Surge motion of $58 \mathrm{~cm}$ draught

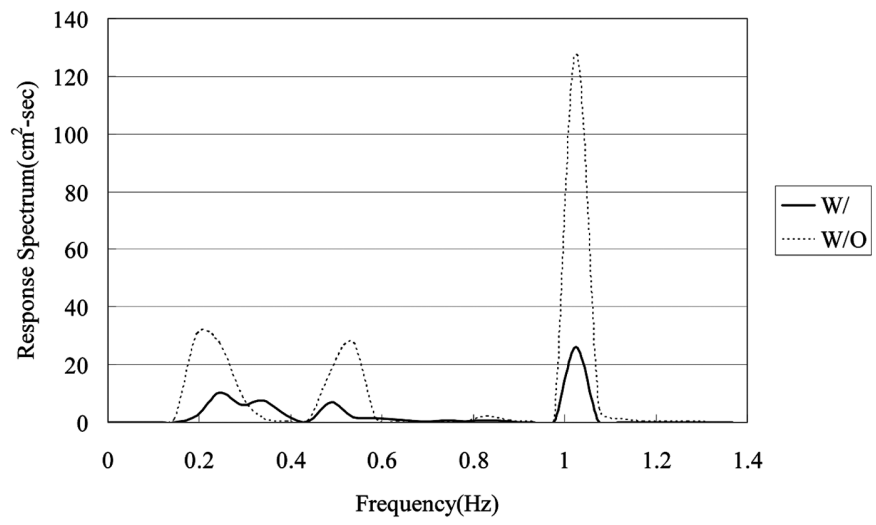

(b) Heave motion of $58 \mathrm{~cm}$ draught

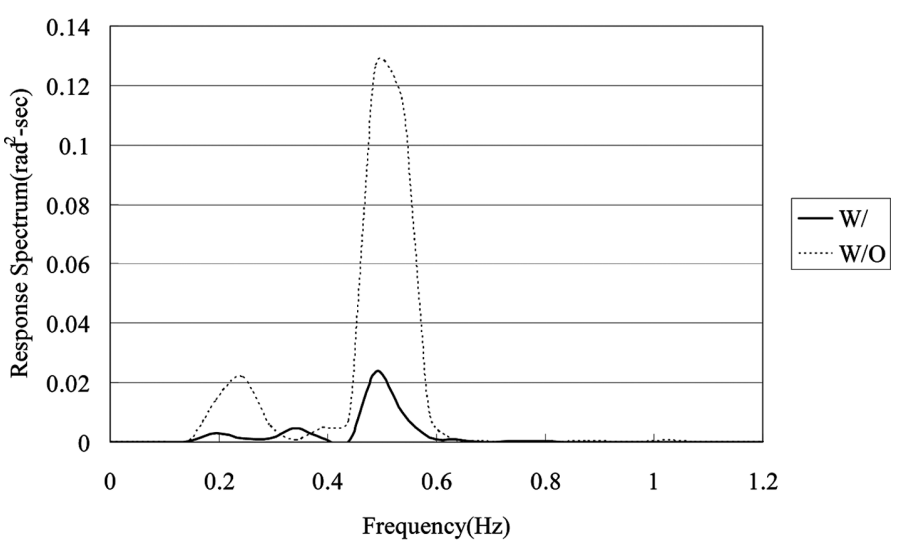

(c) Pitch motion of $58 \mathrm{~cm}$ draught

Fig. 18 Comparison of frequency response for $58 \mathrm{~cm}$ draught $(T=2 \mathrm{sec}, h=6 \mathrm{~cm})$

part (b) of Fig. 17 to Fig. 19, the frequency distribution of heave motions is very scattered. Especially for the case of draught of $55 \mathrm{~cm}$, in the lower frequency zone, the heave response was larger when the TLP equipped with UWTLCD device. A high resonant frequency in heave motion 


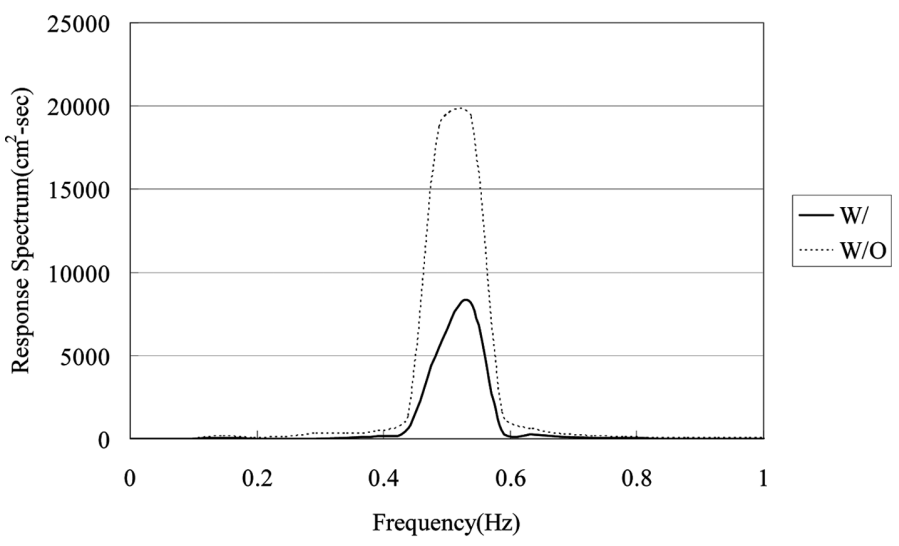

(a) Surge motion of $60 \mathrm{~cm}$ draught

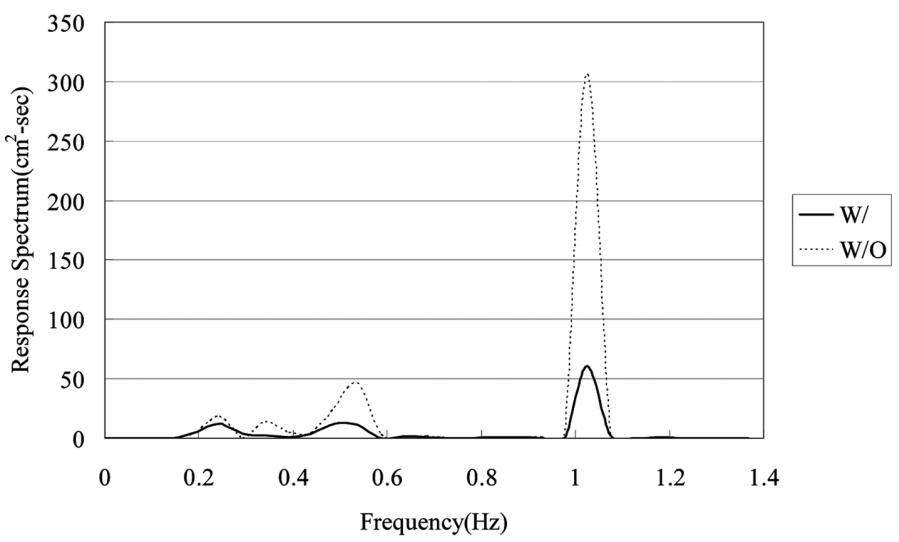

(b) Heave motion of $60 \mathrm{~cm}$ draught

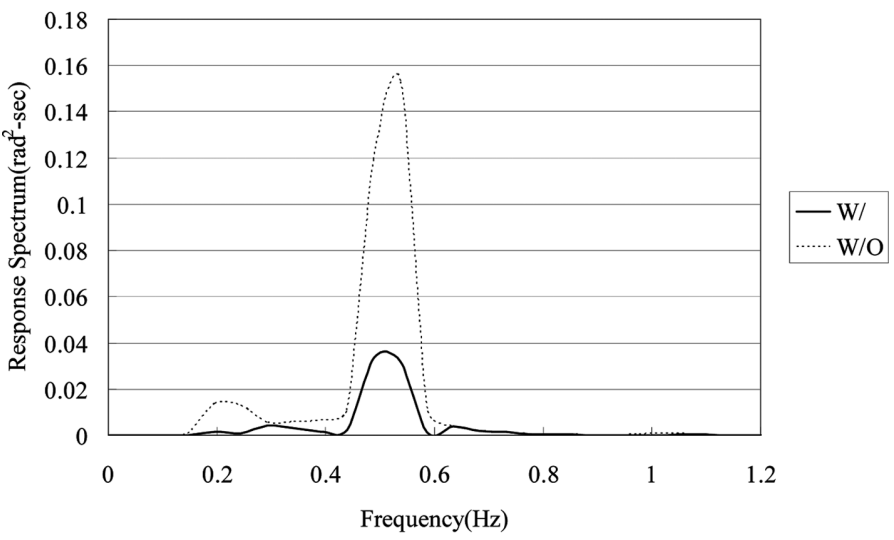

(c) Pitch motion of $60 \mathrm{~cm}$ draught

Fig. 19 Comparison of frequency response for $60 \mathrm{~cm}$ draught $(T=2 \mathrm{sec}, h=6 \mathrm{~cm})$

more than one $\mathrm{Hz}$ was also found the experimental results. In the frequency response of pitch motion as shown in part (c) of Fig. 17 to Fig. 19, a response pattern similar to surge motion was observed, where even though some scattering distribution in the response was shown but, the major 
Experimental study on the vibration mitigation of offshore tension leg platform system with UWTLCD 97

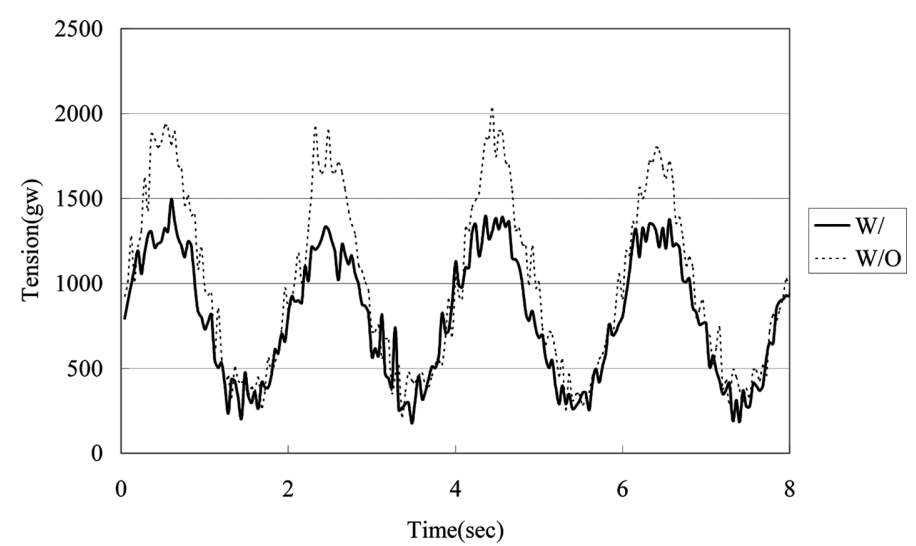

(a) UWTLCD-TLP draught $=55 \mathrm{~cm}$

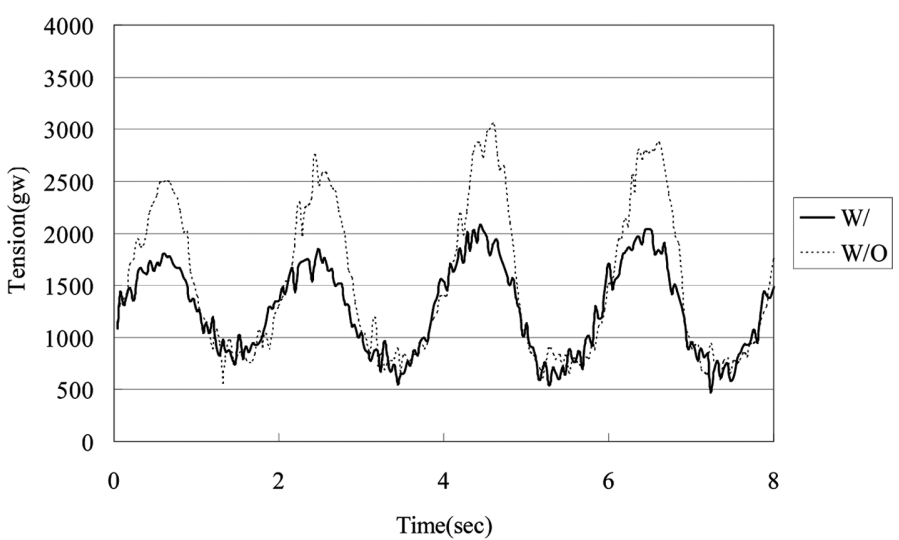

(b) UWTLCD-TLP draught $=58 \mathrm{~cm}$

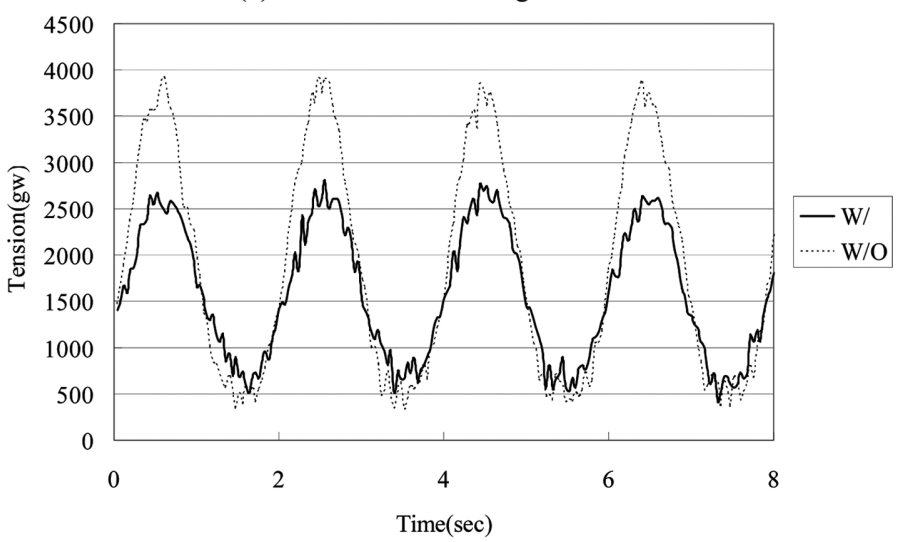

(c) UWTLCD-TLP draught $=60 \mathrm{~cm}$

Fig. 20 Comparison of tension force for various UWTLCD-TLP draughts $(T=2 \mathrm{sec}, h=6 \mathrm{~cm})$

response generally corresponded to surge motions.

The corresponding responses for the tension force of the strained tethers are shown in Figs. 20(a), (b) and (c) as well. Since the increase of the draught means the increase of the pretension force, a deeper draught will cause a larger pretension force, which is shown in Table 2. However, the 


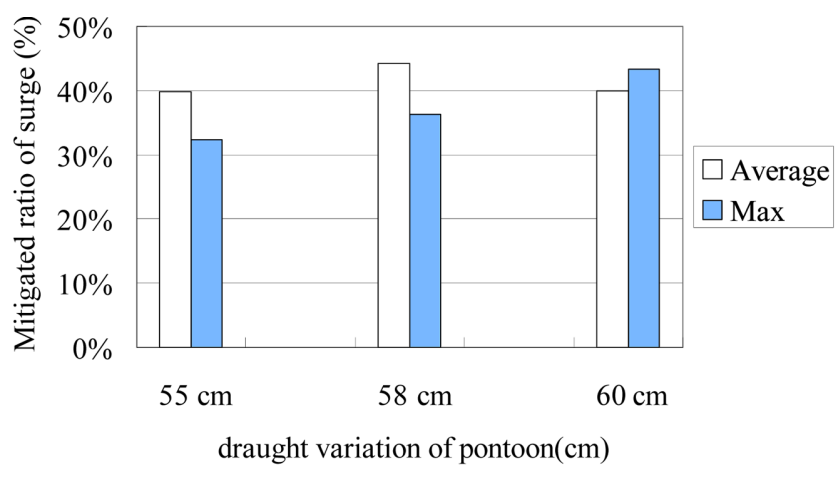

(a) Surge motion

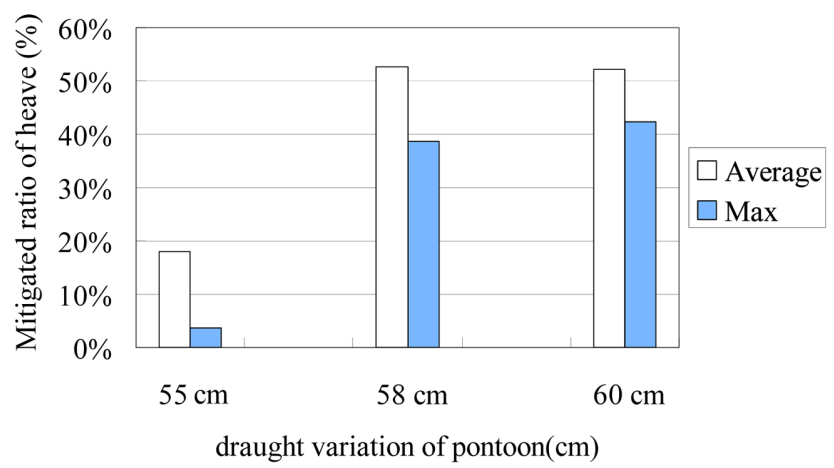

(b) Heave motion

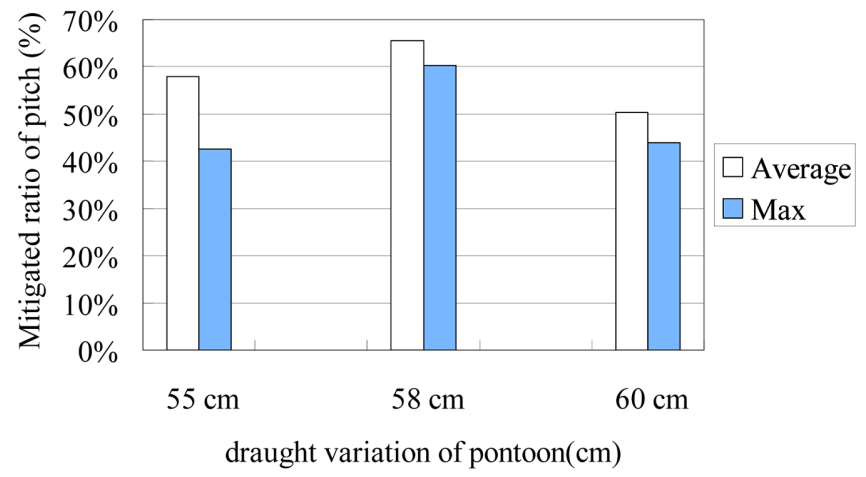

(c) Pitch motion

Fig. 21 The response amplitude reduction ratio for various UWTLCD-TLP draughts

reduction effect is not significantly varied corresponding to the variation of the draught in this case. It is also observed from the reduction on the tether tension as shown in Fig. 19 that UWTLCD tends to produce a more even responses on the TLP compared to the one without UWTLCD, where fluctuating tether tensions are not symmetrical to the initial pretension force. The reduction effect on the responses is also drawn into a column diagram as shown in Figs. 21(a), (b) and (c). For the reduction in the surge motion the mitigation ratio is about $40 \%$ in average and more than $50 \%$ for the pitch motion. However, for the heave motion when the draught depth is smaller such as the case 
Experimental study on the vibration mitigation of offshore tension leg platform system with UWTLCD 99

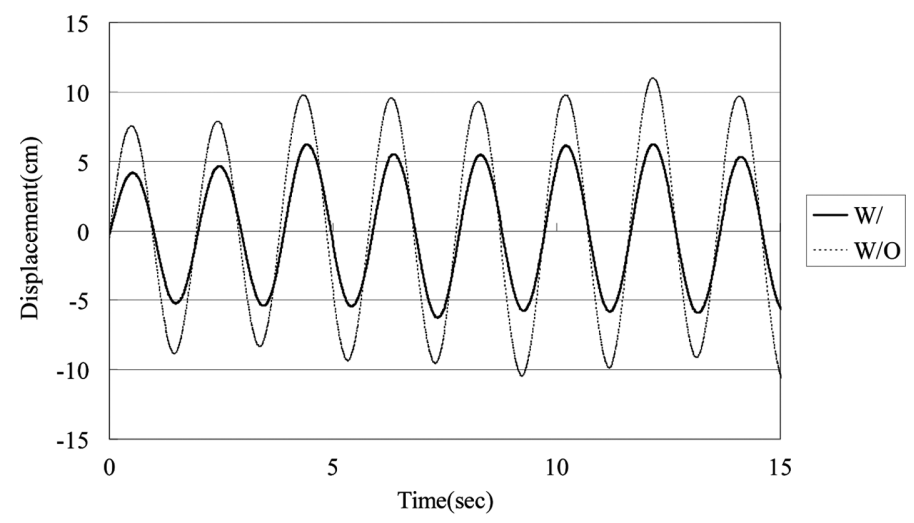

(a) Surge motion

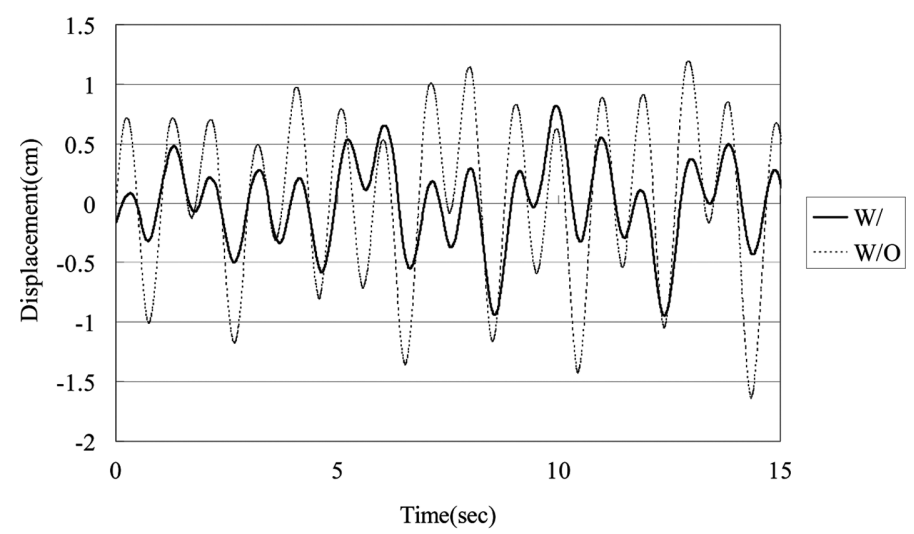

(b) Heave motion

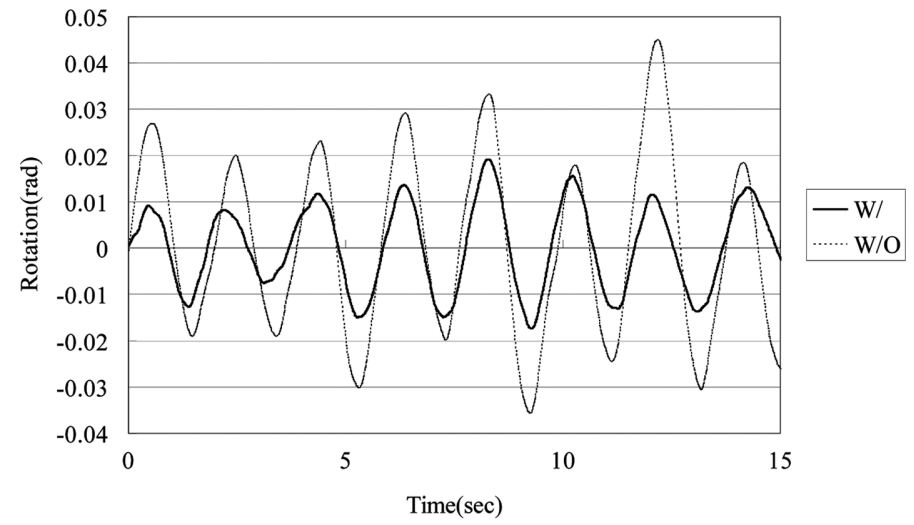

(c) Pitch motion

Fig. 22 Comparison of response in time domain $\left(L_{d}=90 \mathrm{~cm}\right)$

of $55 \mathrm{~cm}$, the mitigation ratio seems to be smaller but for the other two cases, the mitigation effect is still significant as high as $50 \%$. This phenomenon was already observed in Fig. 17, where as indicated in part (b) the frequency response of heave motion, due to a scattered distribution of the responses, the mitigation effect was influenced and reduced. For the same reason as observed in part 


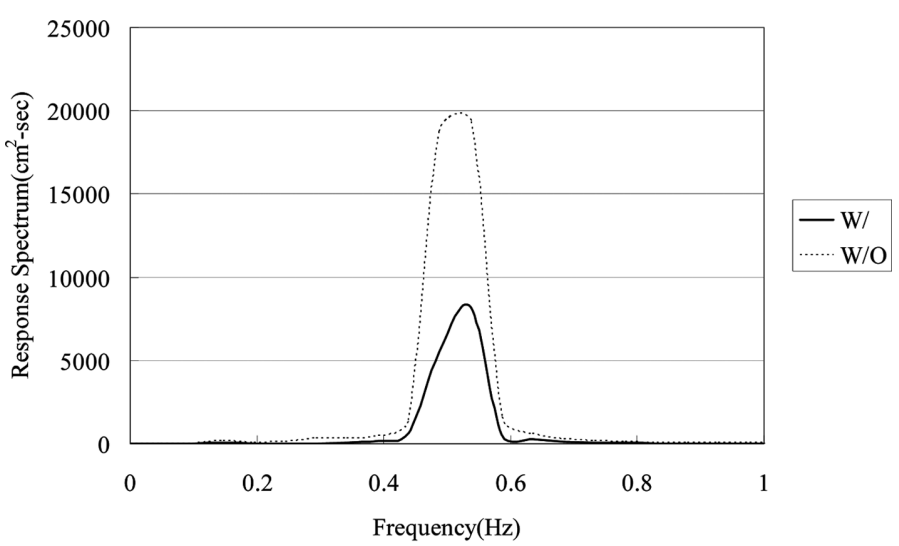

(a) Surge motion

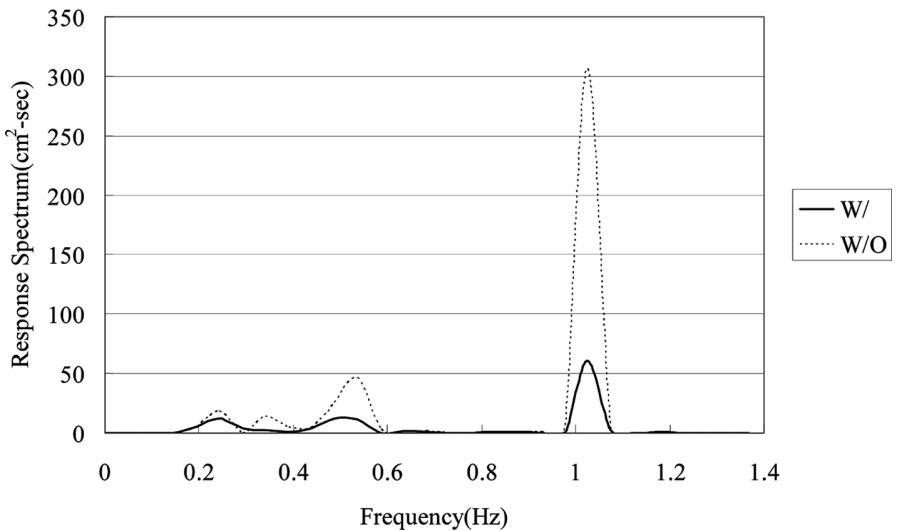

(b) Heave motion

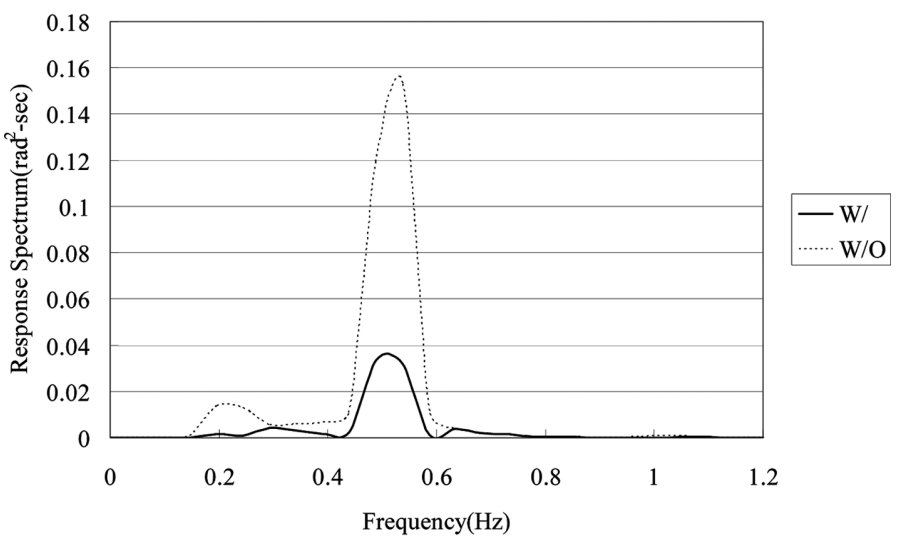

(c) Pitch motion

Fig. 23 Comparison of response in frequency domain $\left(L_{d}=90 \mathrm{~cm}\right)$

(b) of Fig. 18, the $58 \mathrm{~cm}$ draught case, in the lower frequency range the mitigation effect is still good and eventually, the total mitigation effect is much better for this case. 
Experimental study on the vibration mitigation of offshore tension leg platform system with UWTLCD

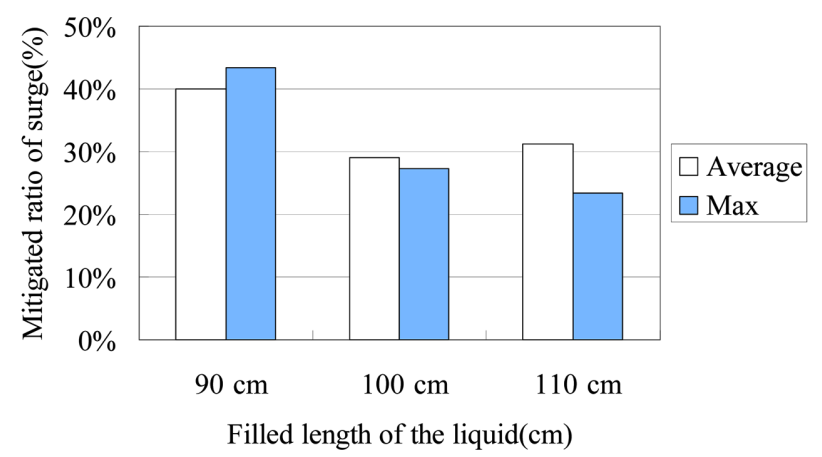

(a) Surge motion

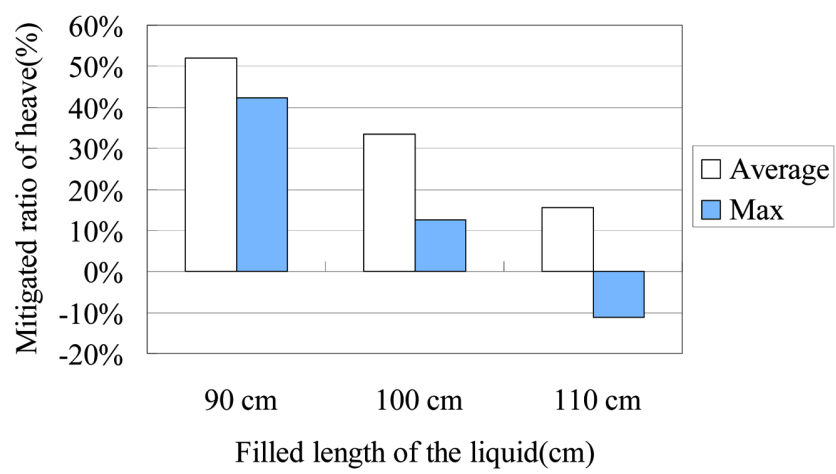

(b) Heave motion

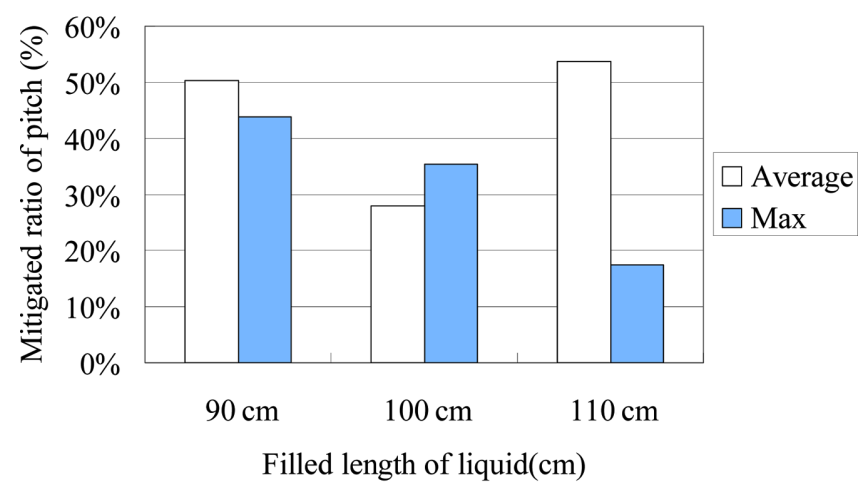

(c) Pitch motion

Fig. 24 Reduction ratio of response amplitude corresponding to various filled lengths of liquid

\subsection{Effect on the variation of filled liquid}

The effect of the mitigation for the response amplitude due to the variation of the filled amount of the liquid is evaluated here. The typical response-comparisons for motions of various degrees of freedom of the model-platform with and without installation of UWTLCD are shown in Figs. 22(a), (b) and (c). The reduction in various motions is again clearly observed. Figs. 23(a), (b) and (c) are spectral responses corresponding to the surge, heave and pitch motion during the test, where 
significant reduction can be observed for all responses. The reduction effect is shown in Figs. 24(a)(c); it can be seen that with increasing length of the filled liquid the reduction effect becomes generally less significant. In the case of the heave motion as indicated in Fig. 24(b), when the tube is filled with more liquid the reduction effect on the heave motion becomes less significant. However, mostly the overall reduction effect can reach as high as $4 \%$ for the surge motion and $50 \%$ for the pitch motion.

\section{Conclusions}

In this study, the traditional TLCD system was modified and applied to an offshore tension leg platform structural system to mitigate the vibration and tension force of the anchoring tethers. Experimental investigation studies were carried out for the mitigation effect of the newly developed under water TLCD (UWTLCD) system. The UWTLCD was designed by firstly, replacing the orifice tube with a smaller horizontal tube and secondly, combing the TLCD system with the buoyant members of the TLP under the water. The modification creates a multipurpose buoyant system associated with vibration mitigation function. On the other hand, the UWTLCD that is installed underwater instead would not occupy any additional space for the platform and yet provide buoyancy to the system. The innovative underwater TLCD (UWTLCD) device with reduced size of horizontal tubes is also the first time to apply to the offshore platform structural system.

The mitigation effect is evaluated corresponding to the variation of wave period and wave-height, the liquid-length in the tube and initial draught of the UWTLCD-pontoon. Corresponding to each set of testing parameters, model-platforms with and without installation of UWTLCD device were constructed and tested in three sets of group. Primarily, the responses in surge, heave and pitch motion of the platform are the main indications for the mitigation observation. Furthermore, the variation in tension force of strained tethers that accounts for the overall motion of the platform was also investigated.

According to experimental testing results, after installation of the UWTLCD device on the offshore platform structural system, the mitigation effect on the vibration amplitude of the platform could reach up to $50 \%$ such as in the case of pitch motion. For the surge motion, it can reach as high as $30 \%$ in general. In the tests of larger wave-height, mitigation effect is better and similar phenomenon is also observed for longer period of waves. Observed from the reduction of tension force in the tension-leg tethers and compared to individual responses of the surge, heave or pitch motion, the reduction in tension force is much more significant, meaning that the overall mitigation is more effective.

In the evaluation for the mitigation effect due to various draughts on the buoyant members, the offshore platform structure with larger draught (higher pretension) seemed to have better performance for the heave motion while the other motions are not affected significantly. As far as the effect to the mitigation of filled length of the liquid in the tubes, the increase of length of the liquid filled in the tubes the mitigation of vibration. Particularly for the heave motion, the over increase of the filled liquid may reduce the mitigation effect.

It is concluded that according to this experimental study, the application of the UWTLCD device to an offshore platform system to ease the wave-induced vibrations is encouraging in terms of its response mitigation and the reduction on the measured tension forces of the TLP tethers. Therefore, the structural safety can be better ensured for the TLP installed with UWTLCD subjected to vibrations from wave motions or operations. 
Experimental study on the vibration mitigation of offshore tension leg platform system with UWTLCD

\section{References}

Balendra, T., Wang, C.M. and Cheong, H.F. (1995), "Effectiveness of tuned liquid column dampers for vibration control of towers", Eng. Struct., 17(9), 668-675.

Boschetti, N. (2006), "Offshore floating foundation (Tension Leg Platform) to support a multimegawatt wind turbine", OWEMES- Civitavecchia.

Brogan, M.A. and Wasserman, K.S. (2003), "Tension leg platform design optimization for vortex induced vibration", Oceans Proceeding, 5, 2894-2902.

Chaiseri, P., Fujino, Y., Pacheco, B.M. and Sun, L.M. (1989), "Interaction of tuned liquid damper (TLD) and structure: theory, experimental verification and application", Struct. Eng. / Earthq. Eng., JSCE, 6, 273-282.

Chatterjee, P.C., Das, P.K.and Faulkner, D. (1997), "A hydro-structural analysis program for TLPs", Ocean Eng., 24(4), 313-333.

Colwell, S. and Basu, B. (2009), "Tuned liquid dampers in offshore wind turbines for structural control", Eng. Struct., 31(2), 358-368.

Fujino, Y., Pacheco, B.M., Chaiseri, P. and Sun, L.M. (1988), "Parametric studies on tuned liquid damper (TLD) using circular containers by free-oscillation experiments", Struct. Eng. / Earthq. Eng., JSCE, 5(4), 381-391.

Fujino, Y. and Sun, L.M. (1993), "Vibration control by multiple tuned liquid dampers (MTLDs)", J. Struct. EngASCE, 119(12), 3482-3502.

Fujino, Y., Sun, L.M. and Pacheco, B.M. (1992), "Tuned liquid damper (TLD) for suppressing horizontal motion of structures", J. Eng. Mech-ASCE, 118(10), 2017-2030.

Gao, H. and Kwok, K.C.S. (1997), "Optimization of tuned liquid column dampers", Eng. Struct., 19(6), 476-486.

Hitchcock, P.A., Kwok, K.C.S., Watkins, R.D. and Samali, B. (1997a), "Characteristics of liquid column vibration absorbers (LCVA) - I", Eng. Struct., 19(2), 126-134.

Hitchcock, P.A., Kwok, K.C.S., Watkins, R.D. and Samali, B. (1997b), "Characteristics of liquid column vibration absorbers (LCVA) - II", Eng. Struct., 19(2), 135-144.

Isaacson, M. (1979), "Nonlinear forces on bodies", J. Waterw. Port C-ASCE, 105(3), 213-227.

Jain, A.K. (1997), "Nonlinear coupled response of offshore tension leg platforms to regular wave forces", Ocean Eng., 24(7), 577-592.

Kareem, A. and Kline, S. (1995), "Performance of multiple mass dampers under random loadings", J. Struct. Control, 3-5, FP5-19-FP5-28.

Lee, H.H. (1997), "Stochastic analysis for offshore structures with added mechanical dampers", Ocean Eng., 24(9), 817-834.

Lee, H.H. (1998), "Seismic and vibration mitigation for the A-type offshore template platform system", Struct. Eng. Mech., 6(3), 347-362.

Lee, H.H. and Wu, R.J. (1996), "Vibration mitigation of structures in the marine environment", Ocean Eng., 23(8), 741-759.

Lee, H.H. and Wang, W.S. (2001), "Analytical solution on the dragged surge vibration of TLPs with wave, large body and small body multi-interactions", J. Sound. Vib., 248(3), 533-556.

Lee, H.H. and Wang, W.S. (2003), "On the dragged surge vibration of a twin TLP system with multi-interactions of wave and structures", J. Sound. Vib., 263(4), 743-774.

Lee, H.H., Wong, S.H. and Lee, R.S. (2005), "Response mitigation on the offshore floating platform system with TLCD", Ocean Eng., 33, 1118-1142.

Mei, C.C. (1978), "Numerical methods in water wave diffraction and radiation", Annu. Rev. Fluid Mech., 10, 393-416.

Newman, J.N. (1977), Marine Hydrodynamics, MIT Press, Cambridge, MA.

Sakai F., Takaeda, S. and Tamaki, T. (1989), "Tuned liquid column damper - new type device for suppression of building vibrations", Proceedings of the International Conference on High-rise Buildings.

Shum, K.M. and Xu, Y.L. (2004), "Multiple tuned liquid column dampers for reducing coupled lateral and torsional vibration of structures", Eng. Struct., 26(6), 745-758.

Taflanidis, A.T., Angelides, D.C. and Scruggs, J.T. (2009), "Simulation-based robust design of mass dampers for response mitigation of tension leg platforms", Eng. Struct., 31(4), 847-857.

Wen, Y.K. (1980), "Equivalent linearization for hysteretic systems under random excitation", J. Appl. Mech-T ASME, 
47(1), 150-154.

Won, A.Y.J., Piers, J.A. and Haroun, M.A. (1996), "Stochastic seismic performance evaluation of tuned liquid column dampers", Earthq. Eng. Struct. D., 25(11), 1259-1274.

Wu, J.C., Shih, M.H., Lin, Y.Y. and Shen, Y.C. (2005), "Design guidelines for tuned liquid column damper for structures responding to wind", Eng. Struct., 27(13), 1893-1905.

Xu, Y.L., Samali, B. and Kwok, K.C.S. (1992), "Control of along-wind response of structures by mass and liquid dampers", J. Eng. Mech.-ASCE, 118(1), 20-39.

Xue, S.D., Ko, J.M. and Xu, Y.L. (2000), "Tuned liquid column damper for suppressing pitching motion of structures”, Eng. Struct., 22(11), 1538-1551.

Yamamoto, T., Yoshida, A. and Ijima, T. (1982), Dynamics of elastically moored floating objects, (Eds. Kirk, C.L. and CML, Southampton), In Dynamics Analysis of Offshore Structures.

$C C$ 